\title{
Application of Propagation Modeling to Verify and Discriminate Ground-Truth Infrasound Signals at Regional Distances
}

\author{
Christoph Pilger ${ }^{1}$, Florian Streicher ${ }^{2}$, Lars Ceranna ${ }^{1}$, Karl Koch $^{1}$ \\ ${ }^{1}$ Federal Institute for Geosciences and Natural Resources (BGR), Hannover, Germany \\ ${ }^{2}$ German Aerospace Center (DLR), Oberpfaffenhofen, Germany \\ Email: christoph.pilger@bgr.de
}

Received November 5, 2013; revised December 11, 2013; accepted December 18, 2013

Copyright (C) 2013 Christoph Pilger et al. This is an open access article distributed under the Creative Commons Attribution License, which permits unrestricted use, distribution, and reproduction in any medium, provided the original work is properly cited. In accordance of the Creative Commons Attribution License all Copyrights (C) 2013 are reserved for SCIRP and the owner of the intellectual property Christoph Pilger et al. All Copyright (C) 2013 are guarded by law and by SCIRP as a guardian.

\begin{abstract}
An infrasound field campaign was performed in 2011/2012 utilizing single infrasound sensors along the great circle path between a known ground-truth source (Ariane 5 engine test facility, Lampoldshausen, Germany) and a regional receiver (German infrasound array IS26, Bavarian Forest) covering a distance of rough $320 \mathrm{~km}$ in total. The gathered recordings provide new insights in the infrasonic wave propagation at regional and near-source distances by comparing measured signals with modeling results within this study. Ray-tracing and parabolic equation approaches are utilized to model infrasound propagation from the ground-truth source to the line profile sensors and explain the obtained detections and non-detections. Modeling and observation results are compared by estimating their amplitude, quantifying amplitude deviations and also considering observed and calculated travel times and celerities. Modeling results show a significant influence of small-scale atmospheric variations in effective sound speed profiles on the propagation pattern, which results in varying tropospheric and stratospheric ducting behavior. A large number of gravity wave profiles are tested to investigate the influences of atmospheric dynamics on the infrasound wave field and improve the modeling results. The modeling is furthermore applied to a case of two potential, contemporaneous and closely spaced infrasound sources. Propagation modeling is used here to resolve the source ambiguity between a ground-based and a higher altitude source giving a strong preference to the latter with respect to the observed infrasonic signatures. The good agreement between modeling and observation results within this study successfully shows the benefit of applying infrasound propagation modeling to the validation of infrasound measurements, verification of ducting behavior and discrimination of infrasound sources.
\end{abstract}

Keywords: Infrasound; Propagation Modeling; Ground-Truth

\section{Introduction}

Infrasound is generated by a variety of different natural and artificial sources such as volcanic eruptions or meteorite entries [1-3] and anthropogenic events such as aircraft/spacecraft signatures or explosions [4-6], respectively. Infrasonic signals from different sources are detected by microbarometers at nearby up to very remote distances (e.g. see [7-9]). Usually, when an infrasonic detection is made, the corresponding source is unknown and can be identified by quantifying arrival time, signal frequency, amplitude, velocity and back-azimuth [10]. However, difficulties in the proper source identification are due to uncertainties introduced by atmospheric variations on the source-to-receiver propagation path, signalto-noise issues and ambiguities in active infrasound sources in the source direction.

In contrast, ground-truth sources are events with wellknown source parameters such as time and exact location, or clearly observed by complementary techniques, so they have well-known back-azimuths and distances from source to receiver. In this case, travel-time and celerity for an observed signal can be quantified and thus additional information is available on how the signal was ducted from the source to a receiver. Alternatively, in- 
formation about the atmospheric conditions on the propagation path can be acquired or verified by inverting observed waveforms and their parameters from groundtruth sources (e.g., [11-13]).

Infrasound propagation modeling (e.g., [14,15]) is used to describe the propagation pattern of infrasonic signatures from a surface or elevated source to a receiving instrument. Aspects of ducting through different altitudes of the atmosphere (troposphere, stratosphere or thermosphere), the extent of shadow zones as well as estimation of amplitudes and sound attenuation can be covered [16-18]. Propagation modeling is applied in this study to verify ducting from a known ground-truth source to a receiver and to discriminate between different potential sources of a signature, also taking into consideration atmospheric conditions and small-scale changes on the propagation path. Certain detections and their observed travel-time and celerity values can only be explained by including unusual propagation conditions, near-field tropospheric ducting and small-scale atmospheric perturbations such as gravity waves [19-22].

In Section 2 of this study, the observational setting of Ariane 5 rocket engine tests as a ground-truth source [23] and infrasound measurements on a line profile of microbarometers towards an infrasound array as measurement setting are described. Two different propagation models, a ray-tracing [24] and a parabolic equation approach [25], described in Section 3, are applied to study infrasonic source-to-receiver paths. Atmospheric background mod- els using ECMWF analysis data, climatologies and finescale gravity wave structures are included for a realistic estimation of wave ducting. In Section 4, results are described and discussed concerning tropospheric and stratospheric wave ducting, estimation of source amplitudes and consideration of atmospheric dynamics. Finally, in Section 5, all results are summarized and conclusions are given.

\section{Measurements}

In a previous study [23], infrasound signals were analyzed from Ariane 5 engine tests in the years 2000-2004 that could be identified at station IS26 of the International Monitoring System (IMS) network of the Comprehensive Nuclear-Test-Ban Treaty Organization (CTBTO). In spring 2011, information was obtained that a new series of engine tests was planned between fall 2011 and spring 2012 at the rocket propulsion testing facility of the German Aerospace Center (DLR) near Heilbronn, Southern Germany $\left(49.287^{\circ} \mathrm{N}, 9.378^{\circ} \mathrm{E}\right)$. Since this setting was favorable for recording these tests along the path to IS26 based on the prevailing winter wind conditions, as had been found earlier [23,26], a field campaign was designed to cover local propagation distances as close as 20 $\mathrm{km}$ to regional distances of IS26, at a range of $320 \mathrm{~km}$. The geographical setting for this field experiment is shown in Figure 1 and a summary of the ground truth information for the different tests is provided in Table 1.

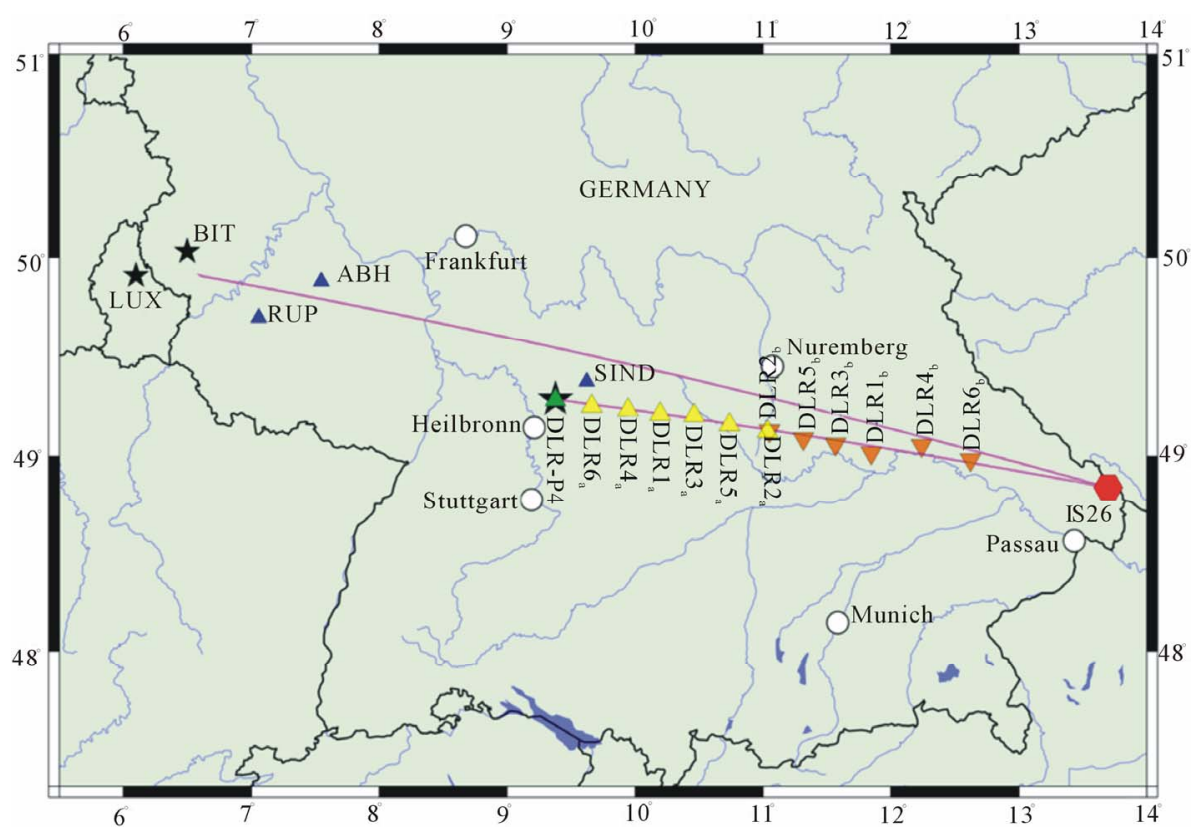

Figure 1. Layout of the field campaign in two different setups (stations DLR1 $1_{a}$ to DLR6 , yellow triangles, from 20 to $120 \mathrm{~km}$ and stations DLR1 $1_{b}$ to DLR6 , orange triangles, from 120 to $240 \mathrm{~km}$ ). Also shown is the Ariane 5 engine test source (black star) near Heilbronn, nearby seismometer and sound pressure level microphone (green triangle, DLR-P4), complementary sources near Bitburg, Germany and in Luxemburg (black stars, BIT, LUX), seismometer stations near the sources (blue triangles, SIND, RUP, ABH) and the IS26 infrasound array (red hexagon) near Passau. 
Table 1. Details of ground-truth information (in black) and observations (in green/red) for nine Ariane 5 rocket engine tests and two additional potential sources (BIT, LUX, see text and Figure 1). Durations for the additional sources are not applicable, since signals are assumed to be impulsive. Positive detections of the source by instruments at a given distance are shown in green, non-detections in red. Instruments set-up but not in operation (and thus not capable of signal detections) are not listed.

\begin{tabular}{ccccccc}
\hline Test Nr. & Date & Start Time & Duration & Seismo-Acoustic & Line Profile Microbarometers & IS26 station \\
\hline 1 & $18-11-2011$ & $15: 50 \mathrm{UTC}$ & $600 \mathrm{~s}$ & $20 \mathrm{~km}$ & - & - \\
2 & $08-12-2011$ & $15: 30 \mathrm{UTC}$ & $668 \mathrm{~s}$ & $20 \mathrm{~km}$ & & \\
3 & $19-12-2011$ & $15: 17 \mathrm{UTC}$ & $646 \mathrm{~s}$ & $20 \mathrm{~km}$ & $40 \mathrm{~km}, 60 \mathrm{~km}, 80 \mathrm{~km}, 100 \mathrm{~km}, 120 \mathrm{~km}$ & $320 \mathrm{~km}$ \\
4 & $16-01-2012$ & $16: 43 \mathrm{UTC}$ & $285 \mathrm{~s}$ & $20 \mathrm{~km}$ & $20 \mathrm{~km}, 40 \mathrm{~km}, 60 \mathrm{~km}, 80 \mathrm{~km}, 120 \mathrm{~km}$ & $320 \mathrm{~km}$ \\
5 & $16-02-2012$ & $13: 28 \mathrm{UTC}$ & $720 \mathrm{~s}$ & $20 \mathrm{~km}$ & $20 \mathrm{~km}, 40 \mathrm{~km}, 60 \mathrm{~km}, 80 \mathrm{~km}, 120 \mathrm{~km}$ & $320 \mathrm{~km}$ \\
6 & $07-03-2012$ & $15: 53$ UTC & $700 \mathrm{~s}$ & $20 \mathrm{~km}$ & $120 \mathrm{~km}, 160 \mathrm{~km}, 180 \mathrm{~km}, 210 \mathrm{~km}, 240 \mathrm{~km}$ & $320 \mathrm{~km}$ \\
7 & $22-03-2012$ & $15: 31$ UTC & $696 \mathrm{~s}$ & $20 \mathrm{~km}$ & $120 \mathrm{~km}, 160 \mathrm{~km}, 180 \mathrm{~km}, 210 \mathrm{~km}, 240 \mathrm{~km}$ & $320 \mathrm{~km}$ \\
8 & $27-04-2012$ & $14: 39$ UTC & $653 \mathrm{~s}$ & $20 \mathrm{~km}$ & $120 \mathrm{~km}, 140 \mathrm{~km}, 180 \mathrm{~km}$ & $320 \mathrm{~km}$ \\
9 & $14-05-2012$ & $15: 21 \mathrm{UTC}$ & $530 \mathrm{~s}$ & $20 \mathrm{~km}$ & $120 \mathrm{~km}, 140 \mathrm{~km}, 160 \mathrm{~km}, 180 \mathrm{~km}$ & $320 \mathrm{~km}$ \\
BIT & $16-02-2012$ & $11: 19$ UTC & N/A & $50 \mathrm{~km}, 60 \mathrm{~km}$ & $240 \mathrm{~km}, 260 \mathrm{~km}, 280 \mathrm{~km}, 300 \mathrm{~km}, 340 \mathrm{~km}$ & $530 \mathrm{~km}$ \\
LUX & $16-02-2012$ & $11: 17$ UTC & N/A & $70 \mathrm{~km}, 100 \mathrm{~km}$ & $270 \mathrm{~km}, 290 \mathrm{~km}, 310 \mathrm{~km}, 330 \mathrm{~km}, 370 \mathrm{~km}$ & $560 \mathrm{~km}$ \\
\hline
\end{tabular}

As only a limited number of six mobile infrasound recording systems was available, a deployment plan was devised to set up a linear station profile with inter-station spacing of about $20 \mathrm{~km}$ in two distinct stages: for approximately half of the initially announced seven engine tests in the distance range from 20 to $120 \mathrm{~km}$ and for the remaining tests to cover, as much as possible, the gap of ranges to IS26. In addition to the mobile infrasound stations we were able to obtain seismo-acoustic waveforms from a seismometer station (SIND) operated by the State Seismological Survey of Baden-Württemberg, Germany (pers.comm.) which was located at a similar range as the closest infrasound station at $20 \mathrm{~km}$, and only at a slightly different azimuth to the source. The specific distances covered in every test can be found in Table 1. The given listing shows that for the first two tests only recordings from the seismometer station (SIND) and IS26 could be obtained, as it was not possible to respond to short-term announcements of these tests with field deployments. However, since DLR announced two additional tests by the time the original tests were concluded, the shorter and the longer range station profiles were covered by three and four engine tests, respectively.

The mobile infrasound equipment consisted of Reftek digitizers and single MB-2000/2005 microbarometers per site. For reducing wind noise for our installations in harsh fall and winter conditions we connected porous hoses of $5-8 \mathrm{~m}$ length to the microbarometers. Additional details on the deployed equipment and the wind noise reduction filters used at the mobile stations are given in [27]. Furthermore, we also put a seismometer about $50 \mathrm{~m}$ from the engine testing facility to monitor the ground-truth source and its temporal stability. For the final test, the sound pressure level was also recorded by the German Aerospace Center, Heilbronn (pers.comm.) at about $24 \mathrm{~m}$ distance to the source. Concerning the infrasound observations from the various tests (see Table 1) and the different profile configurations we found intermittent instances for rather short distances (20 or 40 $\mathrm{km}$ ), lack of signals for more than $40 \mathrm{~km}$ and less than $120 \mathrm{~km}$, and fairly consistent signals at or beyond 120 $\mathrm{km}$ (except in one case) as well as at IS26 where all nine tests were identified, as expected from a testing campaign within winter months [23]. Only the April and May 2012 tests are somewhat extraordinary, because there had not been any observations at IS26 such late in spring for past engine tests. For the quantitative modeling attempted in this study the data were analyzed to determine travel times and pressure amplitudes. Spectral analysis of line profile and IS26 data showed a dominant frequency of $4 \mathrm{~Hz}$, on which we based the modeling described below. For the IS26 infrasound array we also carried out frequency-wavenumber (FK) analyses to confirm the proper azimuth of the signals.

During the field campaign an incidental observation of yet another example of possible ground-truth sources occurred. On 16 February 2012, a few hours prior to one of the Ariane engine tests, rather significant infrasound signals were recorded along the profile of sensors. In the following days, there were media reports about an explosion event in the Grand-Duchy of Luxemburg. The reported site of this explosion was some $240 \mathrm{~km}$ further to the west-northwest of the rocket testing facility and almost on the same great circle path of the recording pro- 
file towards IS26. At the same time there were also reports about a potential sonic boom from a fighter aircraft in the Western parts of Germany, in the Eifel region. The German Air Force confirmed a supersonic flight in this region and eventually provided corresponding groundtruth information about the flight times and path of the relevant aircraft (pers.comm.). The Luxemburg explosion site and an estimated source location on the supersonic aircraft's flight path are also marked in Figure 1 (LUX, $\mathrm{BIT})$. The event was registered by two nearby seismometer stations (ABH, RUP) of the State Seismological Survey of Baden-Württemberg, Germany (pers.comm.), on which the source location estimate of the aircraft was based, along the line profile stations and at IS26 in a distance of more than $550 \mathrm{~km}$. The corresponding distances of the stations to these sources are given in Table 1. The clear observations obtained from the source, either in Luxemburg or over the Eifel region, certainly confirmed the proper operation of the line profile stations that were mostly deployed in the acoustic shadow zone for the early propulsion tests.

\section{Modeling}

Infrasound propagation modeling is carried out within this study to verify detections and non-detections obtained along the line profile infrasound measurements towards the IS26 array. It is also performed to identify and discriminate complementary detections observed during the field campaign.

Propagation modeling approaches utilized within this study are the parabolic equation (PE) algorithm of the software package InfraMAP [25] and the ray-tracing (RT) method HARPA/DLR [24], an enhanced version of the original HARPA ray-tracing program [28]. Realistic atmospheric background conditions are included in the modeling by the use of ECMWF model analysis data (www.ecmwf.int) combined with climatologies for horizontal wind and temperatures above $60 \mathrm{~km}$ (HWM07, see [29]; MSISE00, see [30]). Fine-scale atmospheric structures are introduced in the modeling by using gravitywave disturbances of the effective sound speed following [31].

Figure 2 shows two-dimensional representations of the PE and the RT methods for atmospheric infrasound propagation paths between source and receiver(s). The two methods are shown and described separately in this section/figure, but in the course of the study both are combined in a joint representation for most cases. This should mainly highlight commonalities of the two methods in explaining observations and atmospheric states. Nevertheless, slight differences evident in the comparison of both methods are due to their different approaches (parabolic vs. Hamilton equations), different dimensionalities of modeling space (two-dimensional PE vs. three dimensional RT, of which only two-dimensional projections are shown within this study) and background representations (one-dimensional temperature and wind profile for PE vs. four-dimensional temperature and wind fields for RT). One particular difference is the presence of a weak PE infrasound field that scatters outside the RT ray tubes into shadow zones (e.g. the range between 30 $\mathrm{km}$ and $120 \mathrm{~km}$ in Figure 2). No ray paths are predicted in this region, but a $\mathrm{PE}$ amplitude of about $-60 \mathrm{~dB}$ is modeled. This is due to small amounts of wave energy leaking from wave ducts and scattering into the shadowzone (e.g., [19,21]); a process which can be represented by the used PE but not RT methods. Another difference is a slight horizontal shift of rays returning from the stratosphere in some of the test cases. These differences are inevitable due to the available model versions, but also allow consideration and discussion of infrasound propagation and atmospheric effects on different scales (see Section 4). The main outputs by the two methods are range-height-fields of infrasound wave amplitude for $\mathrm{PE}$ and range-height-views of ray patterns for RT, both modeled for a frequency of $4 \mathrm{~Hz}$ identified as the dominant signal frequency (see Section 2). Further model outputs of surface pressure amplitudes, travel times and celerities are introduced in Section 4.

Atmospheric background parameters, which are essential for the propagation of infrasound, are temperature, zonal and meridional winds from the ground to thermospheric altitudes above $120 \mathrm{~km}$. The effective sound speed, which combines temperature (by temperature-dependent sound-speed) and wind (in the direction of infrasound propagation) into one parameter, controls ducting of infrasound between surface and certain altitudes as e.g. the troposphere, stratosphere and thermosphere. Additional fine-scale structure, e.g. by atmospheric dynamics like gravity waves (see [32]), can furthermore change the effective sound speed and thus modify ducting behavior. Figure 3 shows an exemplary profile of temperature and winds derived from ECMWF, HWM and MSISE as well as the resulting effective sound speed with and without an arbitrary gravity-wave perturbation.

\section{Results and Discussion}

The propagation of infrasound can be subdivided in tropospheric, stratospheric and thermospheric ducts as well as rays escaping the atmosphere [14]. Due to the high signal frequencies of the observations in this study (about $4 \mathrm{~Hz}$ ) and correspondingly increased attenuation in the upper atmosphere, no thermospheric returns are expected or observed.

Detections of Ariane 5 rocket engine signals in the infrasound frequency range have been found during the field campaign at distances from 20 to $320 \mathrm{~km}$. Tropospheric arrivals have been observed in the near field be- 


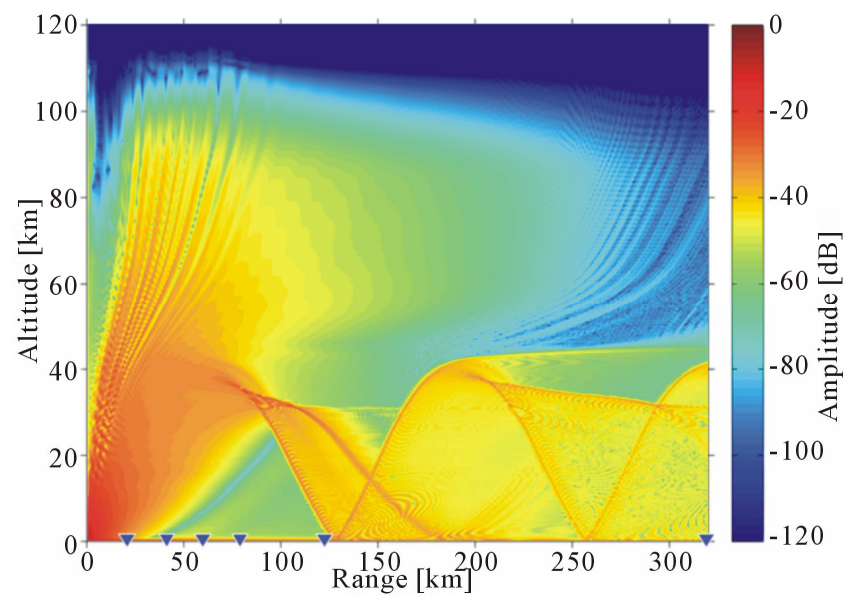

(a)

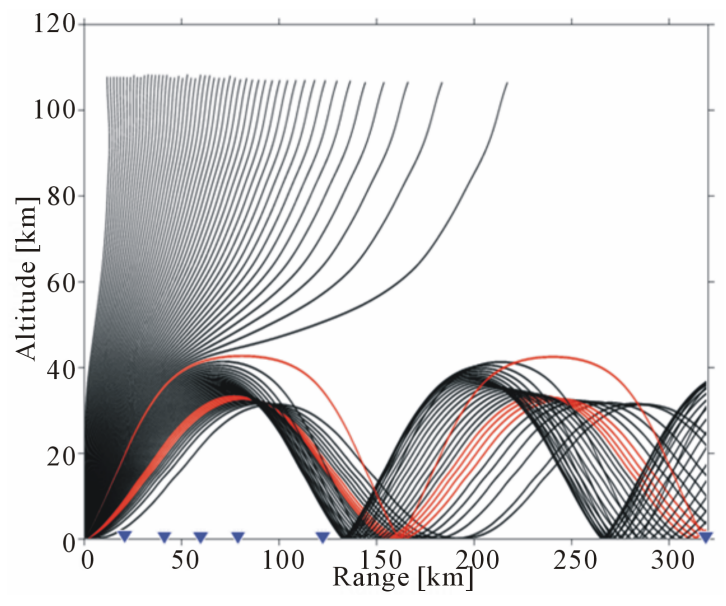

(b)

Figure 2. Infrasound propagation using the parabolic equation (a) and ray-tracing (b) methods. Displayed are the vertical profile from Ariane 5 engine source (origin) to the IS26 array (at $320 \mathrm{~km}$ distance) and altitudes up to $120 \mathrm{~km}$. Propagation conditions are shown for February $16^{\text {th }}, 2012$ (test case \#5). Sound pressure amplitude in dB is color-coded in (a), ray paths shown in (b); ray paths are terminated at the $-120 \mathrm{~dB}$ level (reached at altitudes of approximately $110 \mathrm{~km}$ ), red colored rays indicate eigenrays between the source and the sensors (here only IS26), operational line profile sensors (here between 20 and $120 \mathrm{~km}$ ) are shown by blue triangles.
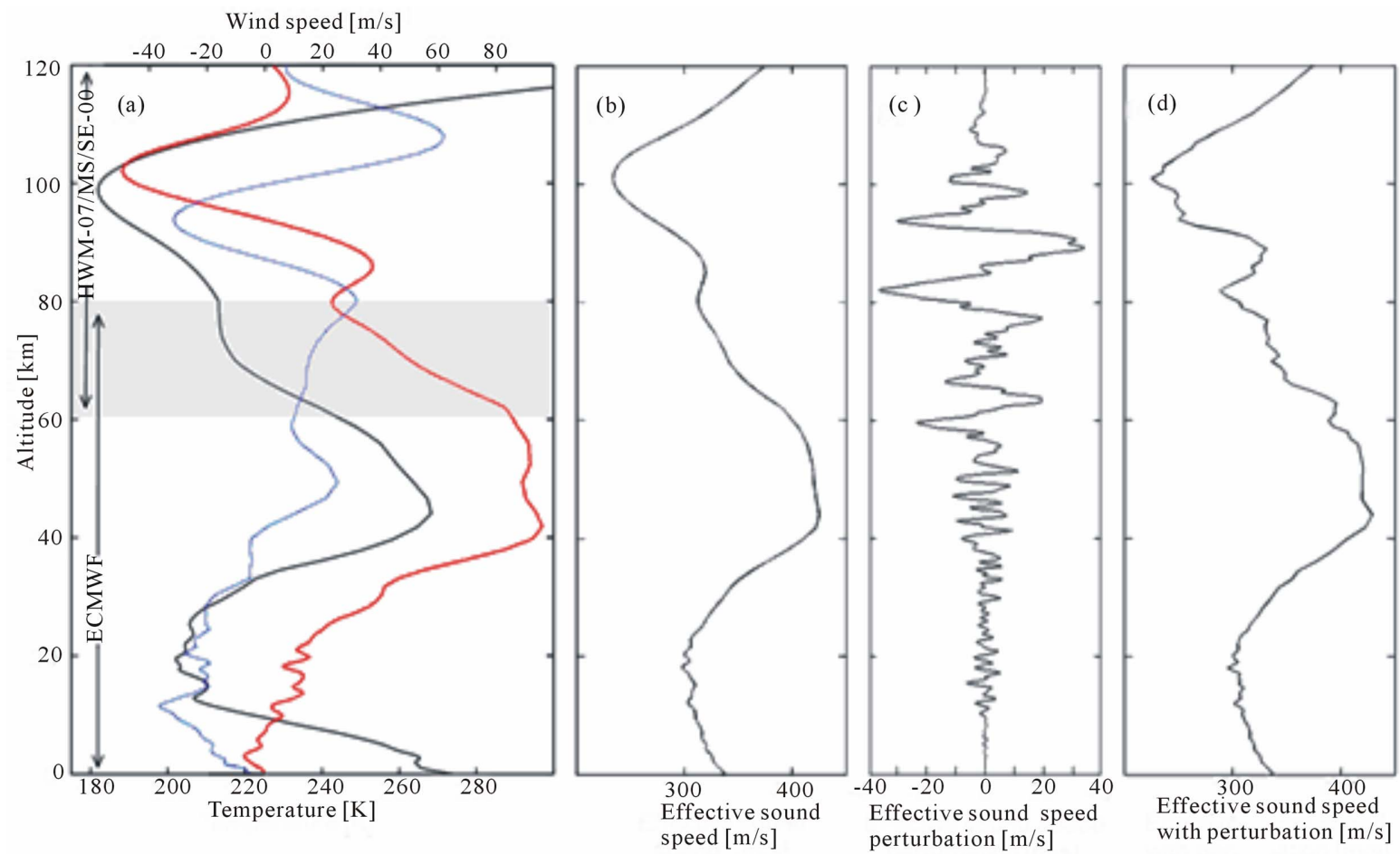

Figure 3. Atmospheric background profiles for (a) Temperature (black), zonal wind (red) and meridional wind (blue), (b) Derived effective sound speed, (c) Effective sound speed perturbation by an arbitrary gravity wave profile, (d) Effective sound speed with the perturbation included. Analysis data and climatologies show the February $16^{\text {th }}, 2012$ conditions (test case \#5).

low $50 \mathrm{~km}$ distance in December 2011 and February 2012 and even at distances above $100 \mathrm{~km}$ in March and April 2012 (see Section 4.1). Detections at longer distances, e.g. at the IS26 infrasound array in $320 \mathrm{~km}$ distance, are of stratospheric origin (see Section 4.2). Fur- thermore, gravity wave influences changing the infrasound ducting characteristics are considered for selected test cases (see Section 4.3). Finally, additional signals obtained during the campaign, are discussed in the context of source discrimination (see Section 4.4). 


\subsection{Tropospheric Ducting}

Detections of tropospheric arrivals were obtained in the near-source shadow zone, where no stratospheric arrivals are predicted, or in the case of April 2012 during a season, where only weak or more likely no stratospheric ducting from west to east takes place. These detections and their association to tropospheric ducting are in good agreement with infrasound propagation modeling. Further seismo-acoustic detections at $20 \mathrm{~km}$ distance (station SIND) for test cases \#1, \#2, \#3, \#5, \#6, and \#8 and non-detections for cases \#4, \#7, and \#9 (see Table 1) confirm the near-field infrasound measurements as well as the modeling. In the following, a few specific examples of tropospheric ducting at regional distances are presented.

Figure 4(a) shows the results of propagation modeling for the 19 December 2011 test case (\#3). Infrasound detections from this case were obtained at 40 and $320 \mathrm{~km}$, while sensors at 60, 80, 100, and $120 \mathrm{~km}$ had no detections. Figure 4(b) shows an enlarged view of the propagation modeling at short distances, highlighting a tropospheric duct. HARPA/DLR ray-trace modeling is superimposed on the PE amplitude field in the figure, both showing a tropospheric duct between the surface and an altitude of a few 100 meters. In the ray-tracing, a number of paths are observed that are each terminated when a limit of ten surface reflections is reached. From this test case and based on the observations and the modeling results, it can be expected that a duct of only a few hundred meters altitude cannot be observed beyond a maximum distance of $10-50 \mathrm{~km}$ distance, i.e. a maximum of $5-10$ reflections. This is due to leaking of the sound energy from the duct, especially when the infrasonic wavelength is in the order of the vertical dimension of the duct and when defocusing by topographic effects near the surface [33] takes place. Unfortunately our PE modeling cannot

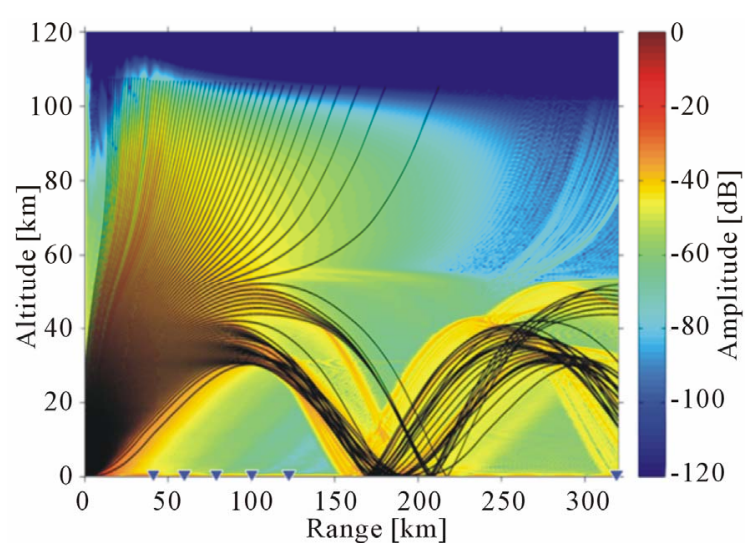

(a) be used to study this scenario in detail, because the 1-D version used here does not allow for inclusion of horizontal variations of background conditions, orography or near-surface attenuation. Therefore the tropospheric duct is removed from the PE model cases in the following considerations of stratospheric arrivals within Sections 4.2 and 4.3 of this paper. The line profile observations as well as a seismo-acoustic detection at $20 \mathrm{~km}$ distance (see Table 1) are in good agreement with the model results based on the meteorological conditions at hand: a layer of higher effective sound speed in approximately $400 \mathrm{~m}$ altitude above the surface, generating a tropospheric duct. At distances larger than $40 \mathrm{~km}$, no signals from the tropospheric duct were found. The detection at $320 \mathrm{~km}$ is of stratospheric origin (see section 4.2). The 16 February 2012 test case (\#5, see Figure 2) is very similar to this case (with a seismo-acoustic and acoustic detection at $20 \mathrm{~km}$, no detections at 40,60 , and $80 \mathrm{~km}$ and stratospheric detections at $120 \mathrm{~km}$ and $320 \mathrm{~km}$ ), and thus not further discussed here.

Figure 5(a) shows modeling results of the 16 January 2012 test case (\#4). The same station-distance-setup is used as for test case $\# 5$, but no detections were made from 20 to $80 \mathrm{~km}$ distance. Detections at 120 and $320 \mathrm{~km}$ are again from stratospheric paths and are discussed in section 4.2. No tropospheric detections were identified and modeling results hence do not show a tropospheric duct. Figure 5(b) shows the same range-height-detail as Figure 4(b) (blue triangles for stations at 20 and $40 \mathrm{~km}$ ), but the PE sound amplitude profile and HARPA/DLR rays are strongly bending upwards. Meteorological conditions cause a decreasing effective sound speed with altitude in the first 10 kilometers and thus inhibit a tropospheric duct, such that the lack of detections and the modeling are again in good agreement.

A case of long distance tropospheric ducting is evidenced by the 27 April 2012 test case (\#8). PE- and RT-



(b)

Figure 4. Combined parabolic equation and ray-tracing profiles for the 19 December 2011 test case \#3. (a) Complete propagation path from Ariane 5 engine source to IS26 infrasound array. (b) Zoom of the first $50 \mathrm{~km}$ horizontal distance and $10 \mathrm{~km}$ altitude highlighting a tropospheric duct. See Figure 2 for further details. 




(a)

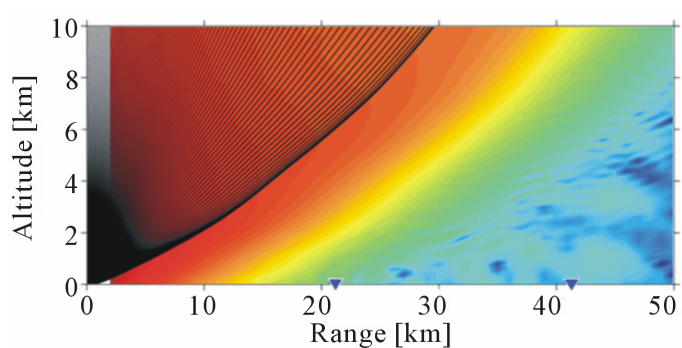

(b)

Figure 5. As Figure 4, but for the 16 January 2012 test case \#4, with atmospheric conditions for which no tropospheric duct was generated.

modeling shown in Figure 6(a) include a tropospheric duct over the whole distance range which is persistent between the surface and an altitude of $3-4 \mathrm{~km}$. Since this altitude is much higher than the few hundred meters in cases \#3 and \#5, tropospheric ducting over large distances is theoretically possible at this altitude [14], as disturbances due to orography and boundary layer turbulence are strongly reduced. Signal measurements by sensors at 120,140, and $180 \mathrm{~km}$ were obtained and could be attributed to tropospheric ducting: Figure 6(b) shows a range versus travel-time plot for the ray-trace model, where incidence points of rays at the surface are compared to travel-times observed by the line profile sensors. Observations between 120 and $180 \mathrm{~km}$ correspond to the modeled tropospheric duct. Their celerity (range over ground divided by travel-time) is about $350 \mathrm{~m} / \mathrm{s}$, which is a fairly high value and thus indicates tropospheric ducting (see $[17,34])$. However, the travel-time estimate for the observation at $320 \mathrm{~km}$ distance is higher than expected for the tropospheric duct. The celerity of this detection is about $300 \mathrm{~m} / \mathrm{s}$, which would be in a typical range for stratospheric ducting [17,34], even though no such duct is predicted by the modeling. Potential explanations for this disagreement between modeling and measurement will be given in Section 4.3. The detection and corresponding modeling of a tropospheric duct reaching out to $180 \mathrm{~km}$ from the source is a rare finding which gives new insights into infrasound propagation at regional distances.

\subsection{Stratospheric Ducting \& Amplitude Estimations}

Classical infrasound propagation from a surface source to a sensor in some hundred kilometers distance is strongly influenced by the stratospheric effective sound speed. During atmospheric conditions, when the effective sound speed in the stratosphere is higher than the effective sound speed near the surface, stratospheric ducting takes place and sound is (repeatedly) refracted from the stratosphere back to the surface. For infrasound propagation from west to east, these conditions normally occur in wintertime in the Northern Hemisphere (e.g. [26]). Since most tests within this study took place during the winter months, stratospheric arrivals at sensors installed at distances of more than $150 \mathrm{~km}$ were expected and regularly observed. For certain test cases (e.g. \#4, \#5 and \#7) with extremely high vertical gradients of the effective sound speed between 30 and $50 \mathrm{~km}$ altitude, stratospheric arrivals were already observed in $120 \mathrm{~km}$ distance from the source. The zonal wind speed in test case \#5 (see Figure 3) increases $70-80 \mathrm{~m} / \mathrm{s}$ between altitudes of $30-40 \mathrm{~km}$, which can be associated, for example, with a strong jet stream. Conditions in test cases \#4 and \#7 lead to similar signal arrivals. Observations of signals in $120 \mathrm{~km}$ distance of the source and their arrival via stratosphere or troposphere are discussed in the course of this section.

Comparisons between modeling results and measurements were also performed with respect to infrasound amplitudes. Amplitudes from modeling were estimated using the surface level output from PE modeling as sound pressure level in decibel $(\mathrm{dB})$ at a reference range of $1 \mathrm{~km}$. For the comparison of these modeling amplitudes with measurements in Pascal $(\mathrm{Pa})$, a reference value for the source amplitude (in $\mathrm{Pa}$ at $1 \mathrm{~km}$ distance) to equalize with $0 \mathrm{~dB}$ is needed.

Figure 7 shows a sound pressure level recording of the last Ariane 5 engine test (\#9) measured at $24 \mathrm{~m}$ distance to the source. For a reference distance of $1 \mathrm{~km}$, this signal of approximately $137 \mathrm{~dB}$ (corresponding to $142 \mathrm{~Pa}$ ) is reduced to a value between $120 \mathrm{~dB}(20 \mathrm{~Pa})$ and $100 \mathrm{~dB}$ (2 Pa) depending on the geometry assumptions for the acoustic loss calculations [35]. Since different source and propagation conditions may occur and thus different 


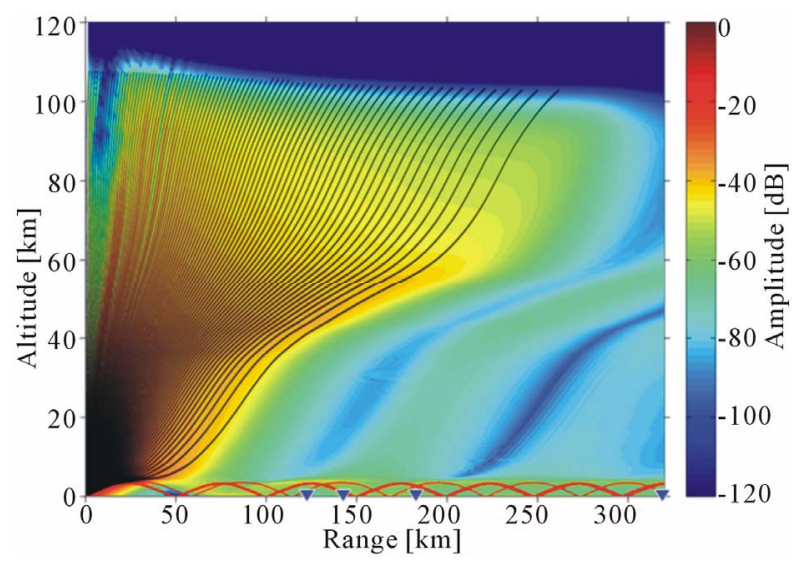

(a)

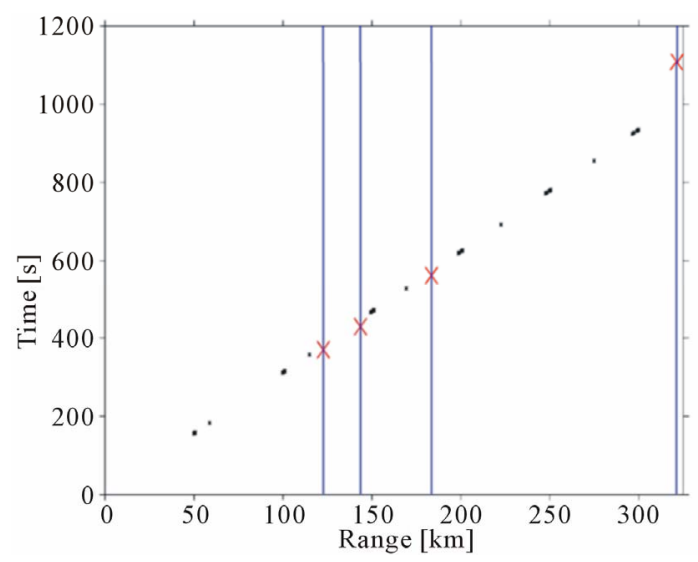

(b)

Figure 6. (a) As Figure 4(a), but for the 27 April 2012 test case \#8 and a tropospheric duct extending to an altitude of 3 - 4 km. (b) Travel time estimation for all ray-tracing surface returns in the tropospheric duct (black dots) and onset-times derived from observations (red crosses) in sensor distances (blue lines).

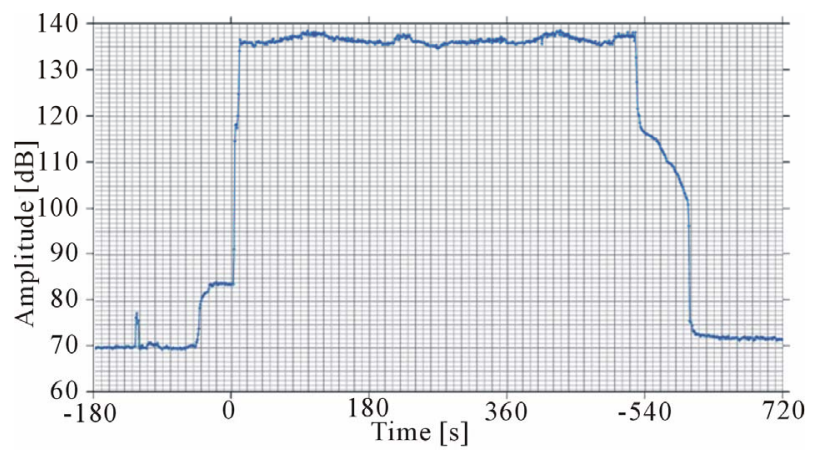

Figure 7. Sound pressure level measurement performed in the audible range during the 14 May 2012 test \#9 at a distance of $24 \mathrm{~m}$ to the Ariane 5 engine. The sound pressure level is increased for the test duration of $530 \mathrm{~s}$ from $70 \mathrm{~dB}$ ambient noise (which is already an increased value due to background noise before and after the test, compared to usually 30 - $50 \mathrm{~dB}$ ) to about $137 \mathrm{~dB}$ during the engine test.

sound pressure levels for different test cases may result, an intermediate value of $10 \mathrm{~Pa}$ source amplitude (at $1 \mathrm{~km}$ ) is chosen corresponding then to $0 \mathrm{~dB}$ modeling amplitude.

Figure 8 shows comparisons of modeled amplitude values derived using the surface level values from the PE method and observed signal amplitudes for the test cases \#3, \#4 and \#5 (already discussed for tropospheric ducting in section 4.1; propagation diagrams for these cases are shown in Figures 2, 4 and 5). Amplitudes derived from modeling and observations are in good agreement and show stratospheric detections at IS26 (at $320 \mathrm{~km}$ ). Furthermore, stratospheric ducting beginning at $120 \mathrm{~km}$ distance explains detections in cases \#4 and \#5 (January and February) but not in case \#3 (December). A beginning stratospheric duct at $120+/-5 \mathrm{~km}$ in the model explains the January and February detections, whereas in December, due to the atmospheric conditions, stratospheric ducting sets in at $150+/-5 \mathrm{~km}$, which is in good agreement with the lack of a stratospheric arrival at $120 \mathrm{~km}$ in that case.

For cases \#3 and \#5 (and \#6 in Figure 9), tropospheric (dotted curves) and stratospheric ducting (dashed curves) were modeled separately. Since the used PE method only allowed one-dimensional background conditions, a tropospheric duct does not fade over the modeling distance. However, both observations and ray-tracing show that the tropospheric ducts vanishes beyond the first observation point and thus the two ducting regimes were combined in these cases by merging the profiles (solid lines) and applying a linear transition from tropospheric to stratospheric ducting.

The root mean square (RMS) deviation was calculated as a measure to quantify the difference/agreement between observations and modeling. For the abovementioned cases, results are $3.26 \mathrm{~dB}$ (case \#3), $8.27 \mathrm{~dB}$ (case \#4) and $25.07 \mathrm{~dB}$ (case \#5), which corresponds to deviations of about one order of pressure magnitude. However, only two to three detections were available for these cases and conclusions on the estimation of amplitudes from this should be drawn with caution.

More specific examples with observations by six sensors are the March 7 and March 22, 2012 Ariane test cases \#6 and \#7 shown in Figures 9 and 10, describing stratospheric duct modeling and corresponding observations in greater detail.

In test case \#6, stratospheric ducting of the engine test signal is observed at distances of 160, 180, 210, and 240 $\mathrm{km}$ as well as IS26 in $320 \mathrm{~km}$. Modeling of the first and second stratospheric return to the surface (see Figure 9(a)) explains most of these observations. Only the observation at the first sensor in $120 \mathrm{~km}$ distance cannot be explained by stratospheric ducting and is (similar to case \#8, see Figure 6) of tropospheric origin. Infrasonic travel 


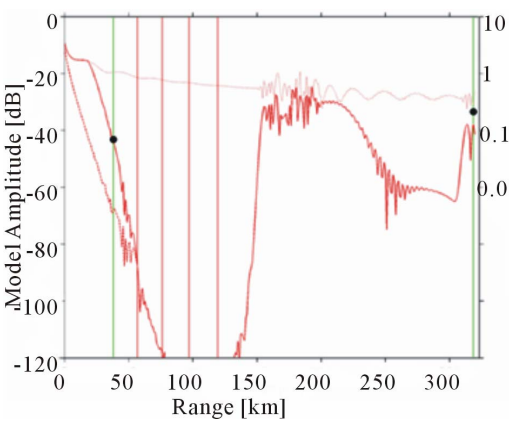

(a)

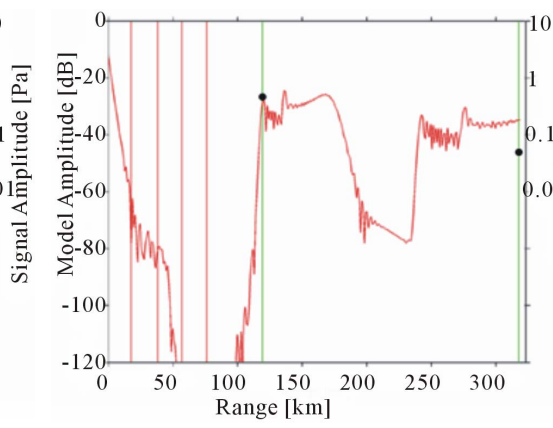

(b)



(c)

Figure 8. Amplitude estimations from parabolic equation modeling (red line, left axis) and measured signals (black dots, right axis) for test cases \#3 (a), \#4 (b) and \#5 (c). Dotted red lines (in (a) and (c), at about 20 - $30 \mathrm{~dB}$ ) indicate amplitudes for a tropospheric duct, dashed red lines (in (a) and (c), from 0 to $20-40 \mathrm{~km}$ ) indicate amplitudes after removal of the tropospheric duct, solid red lines are a transition from tropospheric to stratospheric ducting (only in (a) and (c), while in (b) no tropospheric duct is present). Green vertical lines indicate a signal detection, while red vertical lines indicate a sensor not detecting the engine test signal.

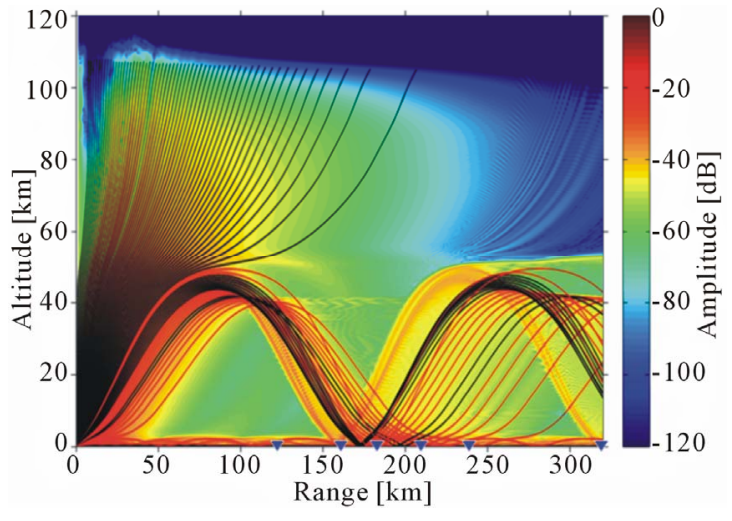

(a)

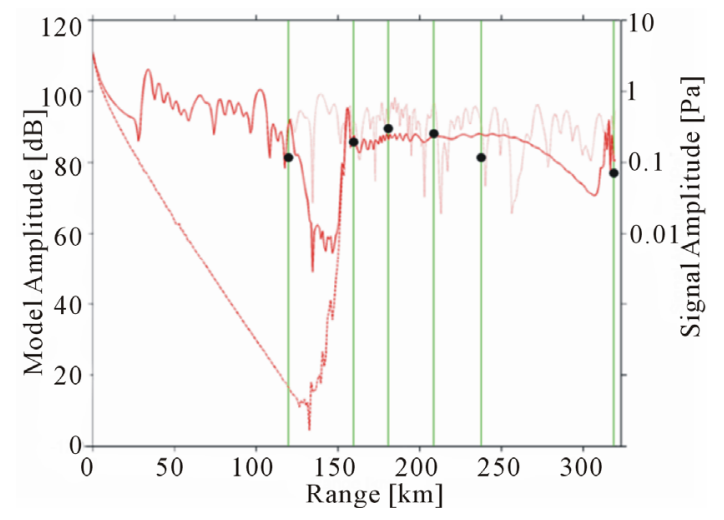

(b)

Figure 9. As Figures 4(a) and 8(a) \& (c), but for the 7 March 2012 test case \#6. The transition region from tropospheric to stratospheric ducting is situated between 120 and $160 \mathrm{~km}$ for this case. The root mean square deviation between modeling amplitude (solid red curve) and observations (at black dots) is $4.70 \mathrm{~dB}$.

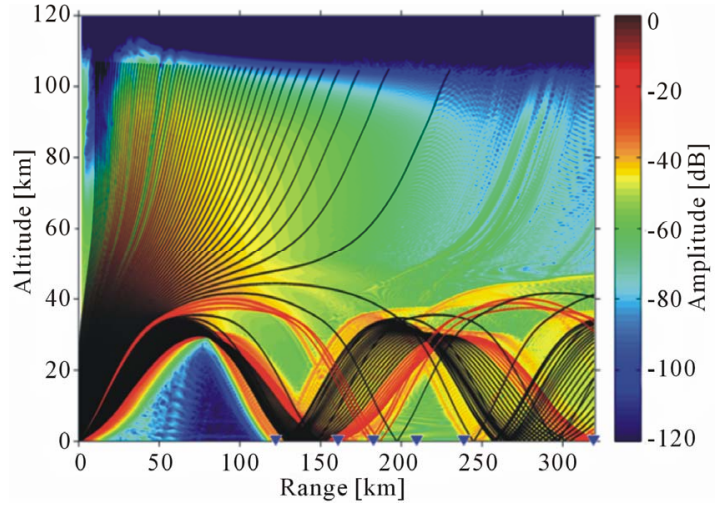

(a)

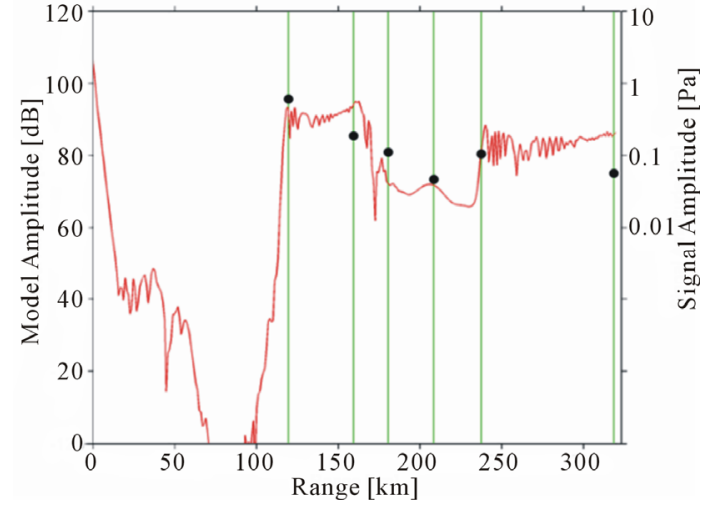

(b)

Figure 10. As Figures 4(a) and 9(b), but for the 22 March 2012 test case \#7. No tropospheric duct is present. The root mean square deviation between modeling amplitude (solid red curve) and observations (at black dots) is $6.69 \mathrm{~dB}$.

times with a celerity of approximately $335 \mathrm{~m} / \mathrm{s}$ (see later Figure 11(b)) and atmospheric conditions where the effective sound speed at $2.5 \mathrm{~km}$ altitude is higher than the effective sound speed at the surface support this conclusion. Figure 9(b) thus combines influences of a tropospheric duct over the first $120 \mathrm{~km}$ distance and removal 
of this duct beyond $160 \mathrm{~km}$ with the same approach as used in Figures 8(a) and (c). The modeling results for pressure amplitudes between 160 and $320 \mathrm{~km}$ are in good agreement with observed signal amplitudes (with a root mean square deviation of the 6 infrasound sensor observations to modeling amplitudes of $4.70 \mathrm{~dB}$ ) and thus explain the infrasound propagation well for this test case.

Figure 10 describes test case \#7, a similar case to Figure 9, with stations (and detections) at the same locations between 120 and $320 \mathrm{~km}$. All detections are now of stratospheric origin, no tropospheric duct is present due to atmospheric conditions, well in agreement with a shadow zone of roughly $100 \mathrm{~km}$ width near the source. First stratospheric returns are modeled and observed at 120 $\mathrm{km}$ distance from the source. For the amplitude changes with distance and especially the reduced detectability at $210 \mathrm{~km}$, between first and second stratospheric reflection, modeling results and observations (with a RMS deviation of $6.69 \mathrm{~dB}$ ) compare favorably.

\subsection{Gravity Wave Dynamics}

The detailed and generally good agreement between modeling results and measurements in different test cases has demonstrated that infrasound propagation modeling is extremely helpful for verification purposes of infrasound measurements from a well-known ground truth source. Estimation of the overall ducting behavior, travel times, and expected amplitudes can be accomplished by a combination of parabolic equation and ray-tracing modeling. However, subtle differences are still occurring between observations and modeling. An example is a non-modeled but obvious stratospheric arrival in test case \#8 (see Figure 6), which might be simulated by considering additional variations of atmospheric conditions missing in the propagation models used so far. Therefore gravity waves are introduced as a main source of atmospheric dynamics and small-scale variations of the effective sound speed, which might suffice for the generation or degradation of atmospheric wave guides or modification of their intensity and range.

Gravity wave dynamics can influence the atmospheric effective sound speed by variations of a few $\mathrm{m} / \mathrm{s}$ near the surface up to variations of some $10 \mathrm{~m} / \mathrm{s}$ in stratosphere and thermosphere. Such modifications of atmospheric background conditions can also change infrasound ducting behavior (e.g., [36,37]), which strongly depends on effective sound speed. An increase of effective sound speed can generate stratospheric ducting or even shorten the distances of stratospheric returns to the surface, i.e. the shadow zone. The consideration of gravity waves by a statistical approach and a high number of random gravity wave profiles in infrasound propagation modeling thus allows completing the picture, where detections of remote infrasound can be expected or where shadow- zones and absent ducts make detections highly unlikely [22].

Figure 11 shows the Ariane test case \#6 again, but with ray paths and travel times for 40 different instances of background conditions including gravity wave effects. Due to a higher number and variation of propagation profiles the ray paths and travel time branches cover a more extended area in range and time and thus even better explain the association of detections to a tropospheric or stratospheric duct. Figure 11(a) shows all potential rays resulting from different gravity wave simulations. It can be clearly seen, that no stratospheric duct, even including gravity waves, would return to the surface before $135 \mathrm{~km}$ distance, so there is no explanation for the 120 $\mathrm{km}$ distance detection other than a tropospheric duct. Figure 11(b) shows travel times for all ray tracing surface returns with different gravity wave realizations. Tropospheric ducting up to $120 \mathrm{~km}$ (with a celerity of approximately $335 \mathrm{~m} / \mathrm{s}$ ) and stratospheric ducting in two different branches (celerities of approximately $300 \mathrm{~m} / \mathrm{s}$ and $280 \mathrm{~m} / \mathrm{s}$ ) can be found and are in good agreement with observed travel time measurements along the line profile and at IS26. Figure 12 shows the same ray tracing and travel time modeling for Ariane test case \#7 (also see Figure 10). All detections including the one at 120 $\mathrm{km}$ can be explained by stratospheric ducting, no tropospheric duct or corresponding celerity above $300 \mathrm{~m} / \mathrm{s}$ is present.

The existence of corresponding ducts in modeling and observation (shown in Figures 9(a) and 10(a)) as well as a comparatively low RMS deviation between modeling amplitudes and observed pressure amplitudes (see Figures 8, 9(b) and 10(b)) already show good agreement for most test cases. Nevertheless, consideration of gravity wave disturbances, as implemented in Figures $\mathbf{1 1}$ and 12, can still increase this agreement and also further reduce the deviation between modeling and measurements.

For test case \#6 (Figure 9b), the RMS deviation between modeling and observation amplitudes was $4.70 \mathrm{~dB}$. Taking into consideration gravity wave modifications of the effective sound speed and thus of the ducting behavior and the model amplitudes derived thereof, this value can be reduced to $3.65 \mathrm{~dB}$ for the best fitting out of 40 gravity wave realizations. For test case \#7 (Figure 10(b)), the RMS deviation of $6.69 \mathrm{~dB}$ can be reduced to $3.96 \mathrm{~dB}$ respectively. These reductions already show the room for improvement of up to $20 \%-40 \%$ by introducing gravity waves.

Instead of applying one fixed gravity wave profile to the complete range of $320 \mathrm{~km}$ and all six observations, one can also apply different gravity wave representations for each point of observation. Since these measurement sites are 20 to $80 \mathrm{~km}$ apart from each other, the atmospheric variability and horizontal changes in gravity wave amplitudes realistically lead to different perturbations 


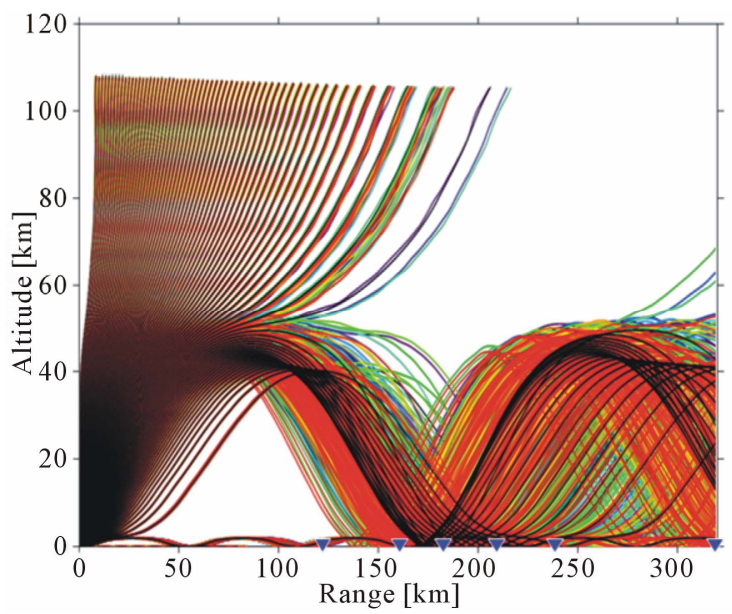

(a)

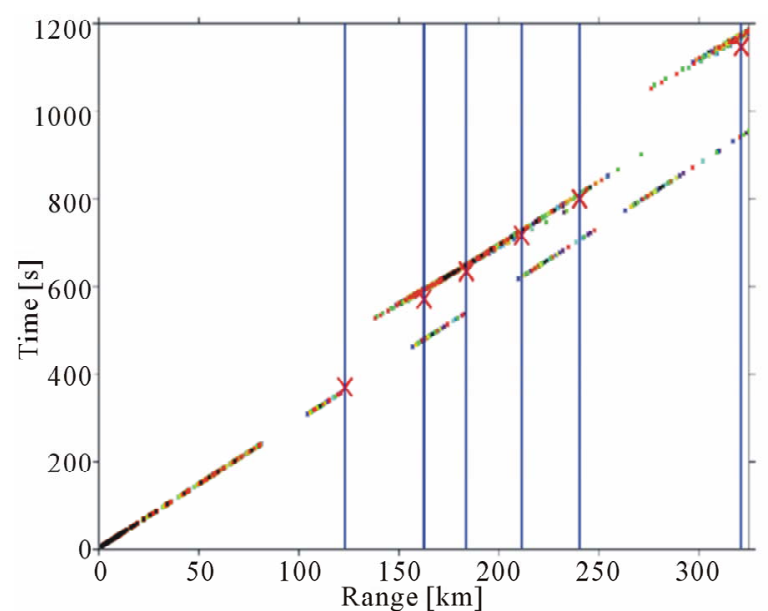

(b)

Figure 11. As Figures 2(b) and 6(b), but for the 7 March 2012 test case \#6 and multiple propagation and travel time representations including 40 different gravity wave profiles (colored). In (a), the original propagation profile (see also Figure 9) is superimposed in black. Travel time branches in (b) for the tropospheric duct and for the stratospheric duct with offsets of 100 and $200 \mathrm{~s}$ and thus decreased celerity are conspicuous.

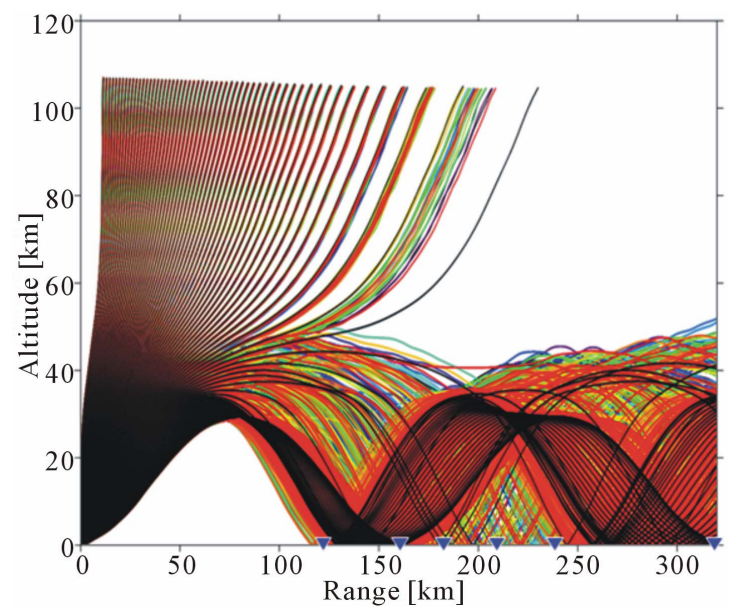

(a)

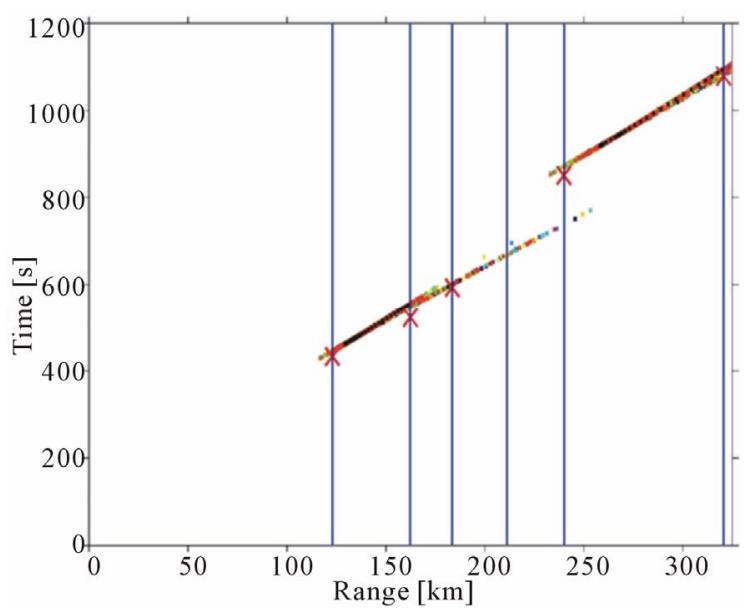

(b)

Figure 12. As Figure 11, but for the 22 March 2012 test case \#7; only stratospheric arrivals are present.

along the observation profile [15,22,31]. However, only a one-dimensional approach for the PE atmospheric background conditions was available within this study, so the described compensation by choosing different gravity wave profiles for the six different measurement sites was applied to show that even more improvement can be achieved. For test case \#6 and the choice of different best-fit gravity wave profiles for each measurement site, the RMS deviation could be further reduced to $2.51 \mathrm{~dB}$, for test case \#7 the value could be reduced to $0.73 \mathrm{~dB}$. These reductions show maximum improvements of $45 \%$ to $90 \%$ by the modeling to observation comparisons considering gravity waves. Table 2 summarizes all RMS values and improvement percentages. Calculation results for the test cases \#3, \#4 and \#5 (Figure 8) are also shown, but the small number of available measurements should be kept in mind, particularly in terms of the achieved improvements (from $27 \%$ to $78 \%$ ).

The impact of gravity wave perturbations can also be an explanation for the generation of stratospheric ducting, where due to seasonal wind direction no such duct is expected in modeling. In such cases the effective sound speed ratio between stratosphere and surface is near to 1 , so that small variations in effective sound speed are sufficient for significantly changing the ducting behavior (see [19,20]).

Figure 13 shows gravity wave effects considered in Ariane test case \#8, occurring end of April 2012. The stratospheric wind already changed after the spring equinox from winterly eastward to summerly westward direction and no infrasound propagation related to a stratospheric duct is expected for this test (see Figure 6). 


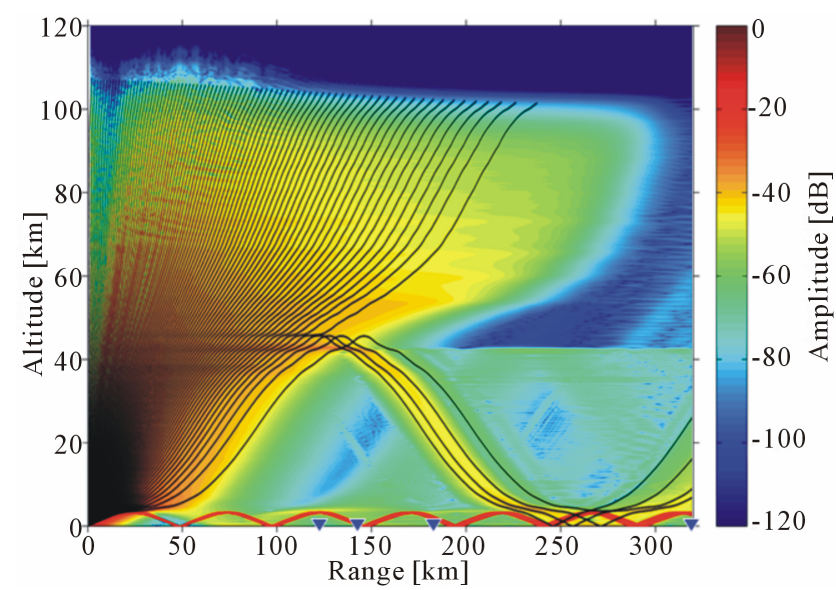

(a)

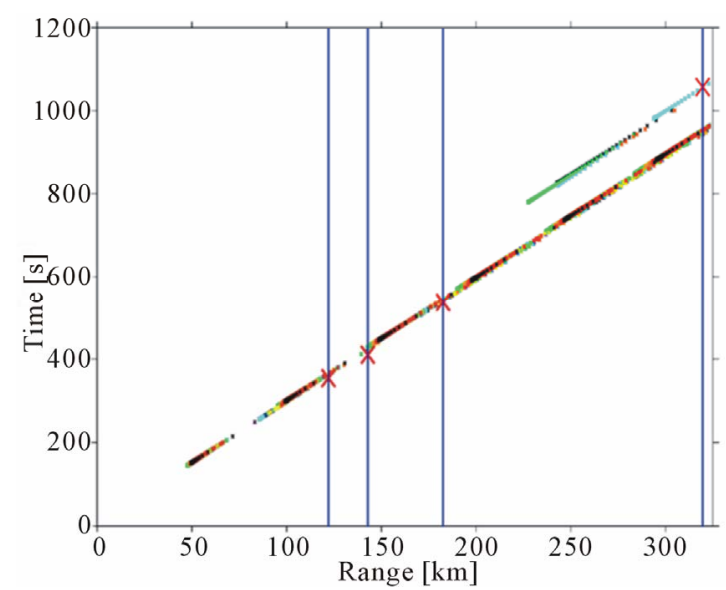

(b)

Figure 13. As Figures 4(a) and 11(b) but for the 27 April 2012 test case \#8. Modeling in (a) shows the propagation with one selected gravity wave profile included (generating a stratospheric duct in contrast to Figure 6(a)). Modeling in (b) shows travel time branches with 40 gravity wave representations (generating a stratospheric branch in contrast to Figure 6(b)).

Table 2. Table showing the root mean square deviations (RMSD) and percentage of improvement for test cases \#3 to \#7; only cases \#6 and \#7, shown in green, have detections at all six measurement sites. The minimum RMSDs and maximum improvements are calculated for realizations with no gravity wave profiles (column 3), one common gravity wave profile (columns 4 and 5) and different individual gravity wave profiles (columns 6 and 7).

\begin{tabular}{ccccccc}
\hline Test Nr. & $\begin{array}{c}\text { Number of } \\
\text { measurement sites }\end{array}$ & $\begin{array}{c}\text { RMSD, no GW } \\
\text { profile [dB] }\end{array}$ & $\begin{array}{c}\text { RMSD, common } \\
\text { GW profile [dB] }\end{array}$ & $\begin{array}{c}\text { Improvement to } \\
\text { "no GW" case [\%] }\end{array}$ & $\begin{array}{c}\text { RMSD, individual } \\
\text { GW profiles [dB] }\end{array}$ & $\begin{array}{c}\text { Improvement to } \\
\text { "no GW" case [\%] }\end{array}$ \\
\hline 3 & 2 & 3.26 & 2.37 & 27 & 1.47 & 55 \\
4 & 2 & 8.27 & 5.59 & 33 & 4.73 & 43 \\
5 & 3 & 25.07 & 6.00 & 76 & 5.59 & 78 \\
6 & 6 & 4.70 & 3.65 & 24 & 2.51 & 46 \\
7 & 6 & 6.69 & 3.96 & 40 & 0.73 & 89 \\
\hline
\end{tabular}

Nevertheless, detections between 120 and $180 \mathrm{~km}$ are obtained due to an elevated tropospheric duct, whereas the detection at IS26 in $320 \mathrm{~km}$ distance has a celerity of $300 \mathrm{~m} / \mathrm{s}$ indicative of a stratospheric duct although no such duct appeared in section 4.1 modeling. Figure 13(a) shows a representation of varying the atmospheric background profile for this test case with a gravity wave perturbation thereby generating a stratospheric duct. Only a few of the 40 gravity wave perturbations considered here generated this duct, so a stratospheric branch in Figure 13(b) is rarely filled with ray trace returns. However, its overall celerity fits well to the observations and gives the best explanation for the detections made at this distance. Thus the consideration of gravity wave dynamics is an important tool for identification and verification of observed infrasound signals and gravity wave representations should be included in infrasound propagation modeling.

Figure 14 shows the same propagation and travel time modeling for the last Ariane test case \#9, which took place in mid-May 2012. Considering normal propagation models and neglecting the effects of atmospheric dynamics, no stratospheric ducting is expected after the end of the winter season, when the stratospheric winds already reversed. However, by including selected gravity wave disturbances (one example shown in Figure 14(a)), stratospheric returns can be modeled in approximate accordance to observations at IS26. The non-detections at the line profile stations in $120,140,160$, and $180 \mathrm{~km}$ are also quite well explained by Figure 14(b). Thus, the rare detections of stratospheric returns for two test cases in late spring (celerity in both cases approximately $300 \mathrm{~m} / \mathrm{s}$ ) are consistent with a modeling taking gravity wave effects into account.

\subsection{Source Discrimination}

Beside the ground truth source detections of the Ariane test cases described above, complementary detections of other potential infrasound sources were found during the field campaign. Especially one prominent observation [27] of a transient signal with several phases at all five line profile stations and IS26 is investigated in greater 


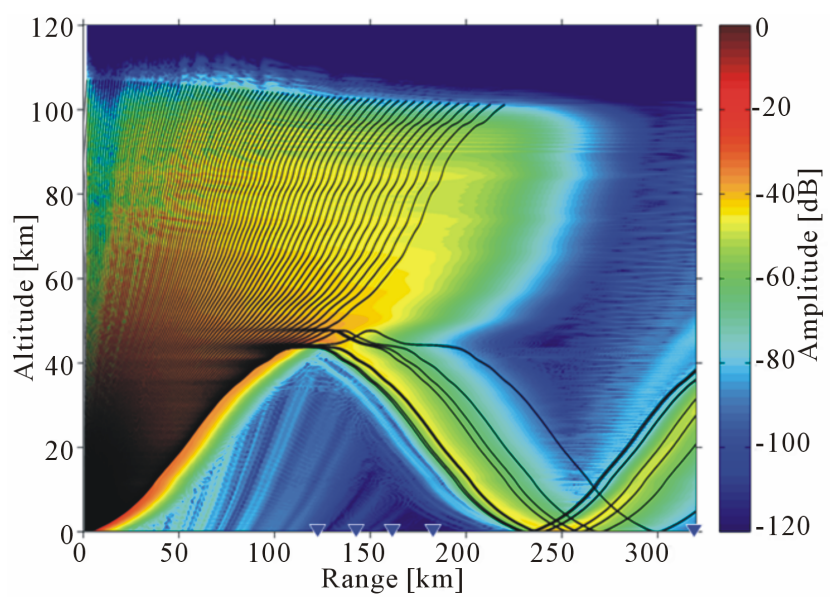

(a)

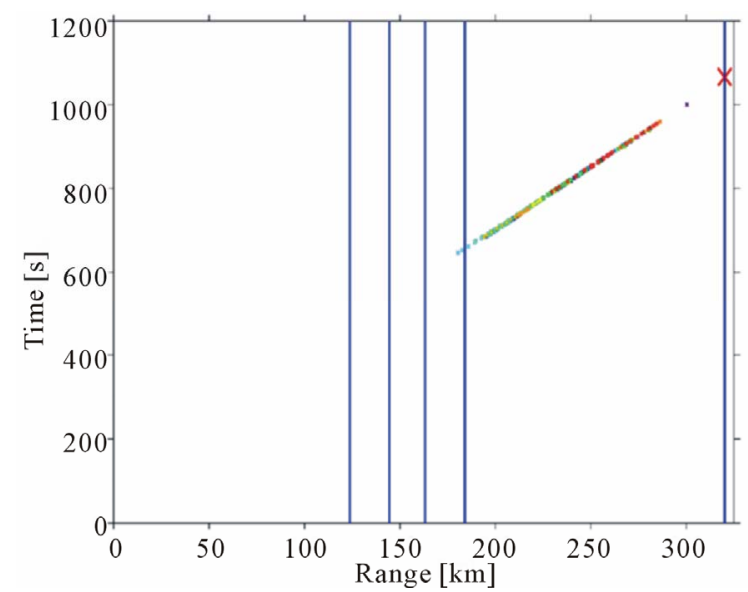

(b)

Figure 14. As Figure 13 but for the 14 May 2012 test case \#9; a stratospheric duct is generated only by including certain gravity wave representations.

detail, because its potential origin is ambiguous. Considering back-azimuth and travel time, both a surface explosion and a supersonic boom at higher altitude are possible sources.

Infrasound propagation modeling from both potential sources to the line profile stations and IS26 is shown in Figure 15. Modeling was performed first for a groundbased source near Flebour, Luxemburg (a) and second for an elevated source at $10.8 \mathrm{~km}$ altitude near Bitburg, Germany (b). Differences in the propagation pattern occur due to different ray paths: For case (a), classical stratospheric ducting takes place by ray paths starting from the surface upwards and reflecting in the stratosphere; for case (b), sound from an elevated source can move upwards, downwards or nearly horizontal, leading to an increased number of different ray paths, smaller shadow zones and ducting of rays in approximately $10 \mathrm{~km}$ altitude. Both modeling approaches correspondingly show these differences and thus indicate characteristics for source discrimination.

Accordingly, Figure 16 shows travel times for all rays impinging with the surface for both modeling cases. While for the Ariane 5 engine test source only one branch of a signal with a duration similar to the test duration arrives at the observing stations, for the observed signal on 16 February 2012 more than one signal phase is observed. An infrasonic signal propagates along different propagation paths to reach the same receiver (e.g., [6]). If the source is very impulsive, different signal onsets (travel time branches) can be distinguished in one observation [27], even if pulse separation is in the order of only tens of seconds.

Differences in travel time branches shown in Figure 16 are caused by the different source altitudes and propagation patterns. For a surface source, only one branch of stratospheric travel times is modeled to arrive at the line profile stations and two branches of stratospheric returns arriving at IS26. For an elevated source it is two arrivals at the line profile stations and four arrivals at IS26. Comparing modeling results with observations, it can be seen, that at least three to four phase arrivals are observed at the line profile stations and up to six arrivals at IS26. This observation favors an elevated infrasound source as origin of the signatures due to a higher number of different travel time branches and phase arrivals.

A comparison of the measured amplitudes with modeling results for the potential ground-based and elevated sources is shown in Figure 17. As the PE method does not yield time-dependent amplitude values, all observations and modeling results are summarized in one range vs. amplitude representation. For the comparison, a $1 \mathrm{~Pa}$ observed signal amplitude was arbitrarily set to correspond to a $-30 \mathrm{~dB}$ modeling amplitude as a best-fit choice since the source amplitude is unknown. The PE amplitudes are the surface level estimates as outlined before (see section 4.2). From the ray-tracing additional estimates of minimum, maximum and average amplitudes were deduced when considering geometric spreading loss for three different intensities (i.e. $10 \mathrm{~dB}, 15 \mathrm{~dB}$ and $20 \mathrm{~dB}$ for cylindrical, intermediate and spherical loss).

The ground-based source (a) is characterized by larger shadow zones before and between the multiple stratospheric returns to the surface, and thereby the groundbased source modeling shows a high variation with distance in the absolute amplitudes (e.g. a jump between -25 and $-60 \mathrm{~dB}$ at $200 \mathrm{~km}$ distance), but a weaker spreading (variance) of neighboring values (i.e. about 5 $10 \mathrm{~dB}$ variation from point-to-point). The elevated source (b) generated smaller and weaker shadow zones, a smoother variation of absolute amplitudes (e.g. only a 10 - $20 \mathrm{~dB}$ jump at $200 \mathrm{~km}$ ), but a higher spreading (i.e. 10 - 


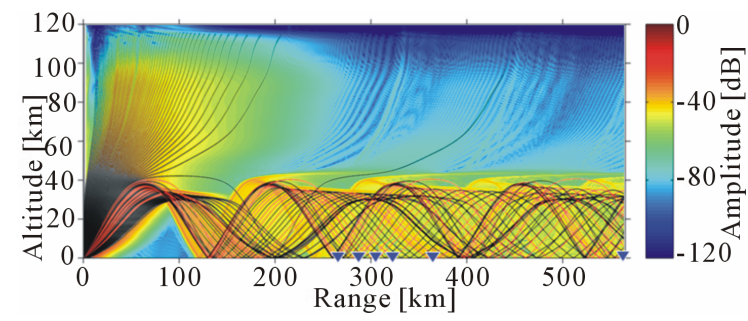

(a)

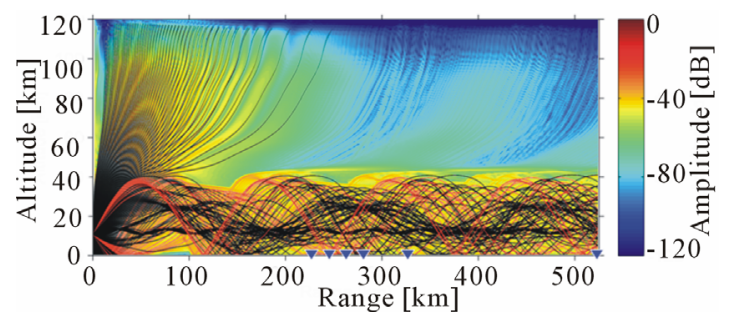

(b)

Figure 15. As Figure 4(a), but for two different scenarios as potential explanations for the 16 February 2012 transient detection. Propagation from two potential sources toward IS26, passing the line profile stations nearby, is shown. (a) Source is a farm explosion in Flebour, Luxemburg, located at $49.914^{\circ} \mathrm{N}, 6.104^{\circ} \mathrm{E}$. (b) Source is a supersonic flight above Bitburg, Germany, located at $50.03^{\circ} \mathrm{N}, 6.5^{\circ} \mathrm{E}$ and in $10.8 \mathrm{~km}$ altitude.

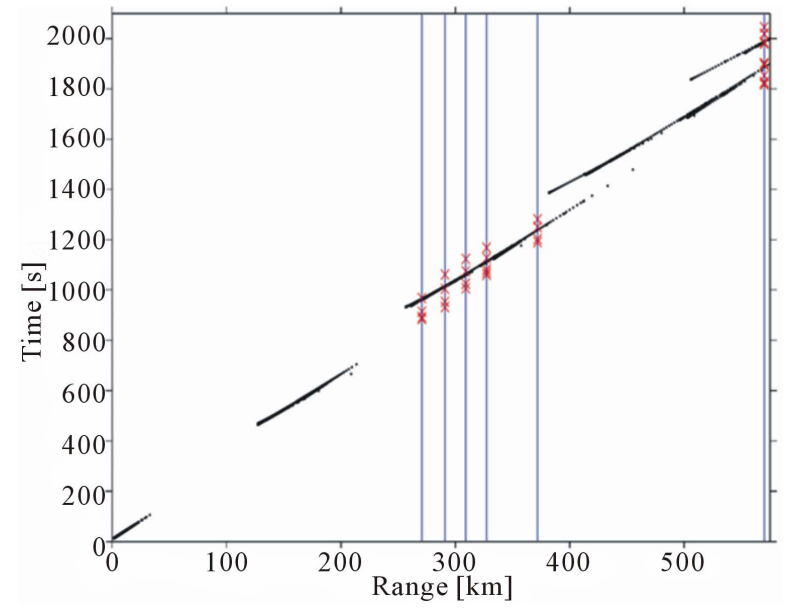

(a)

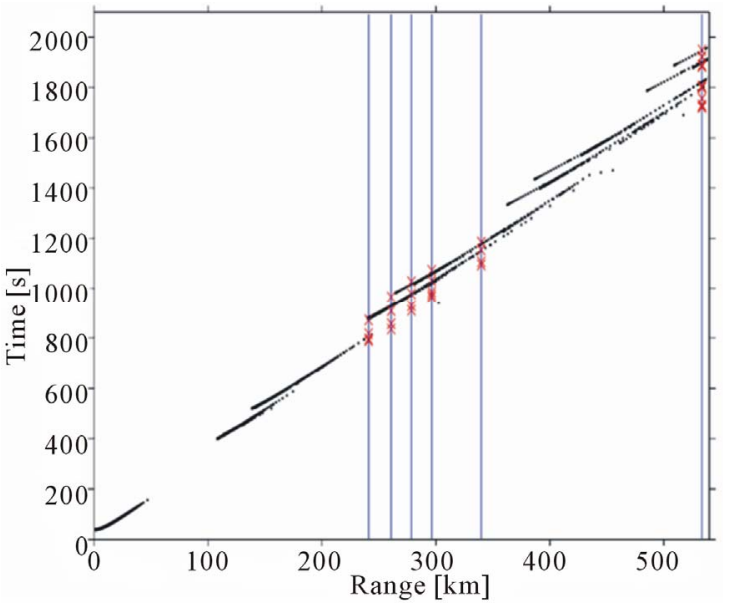

(b)

Figure 16. Travel time modeling and observations (as Figure 6(b)) in two different scenarios, as described in Figure 15. (a) Luxemburg farm explosion, (b) Bitburg supersonic flight. Multiple phase detections with different travel times at the line profile stations and at IS26 are represented by multiple red crosses.

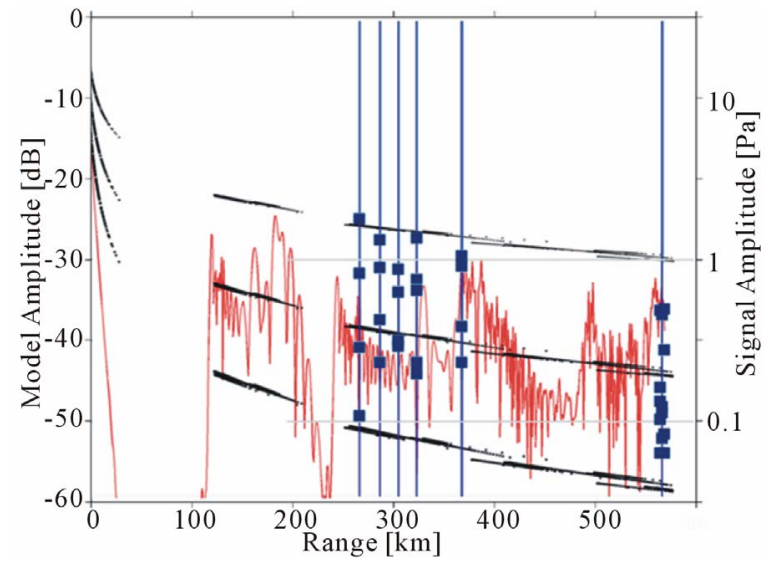

(a)

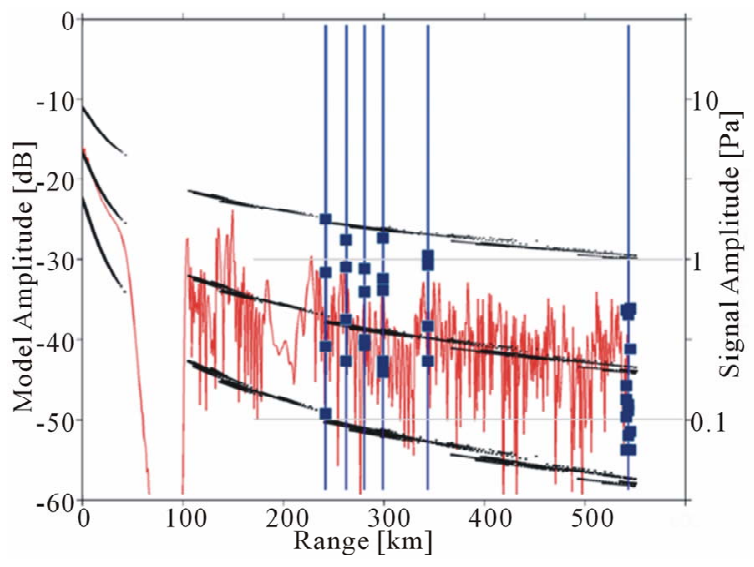

(b)

Figure 17. Amplitude estimations (as Figure 8) for the two different scenarios, as described in Figure 15. Modeling was performed by parabolic equation (red curve, left axis) and ray tracing methods for three different spreading loss estimates (of 10 $\mathrm{dB}, 15 \mathrm{~dB}$ and $20 \mathrm{~dB}$, black curves, left axis), also shown are the measured amplitudes for different phase arrivals at the different sensors (blue boxes, right axis). (a) Luxemburg farm explosion, (b) Bitburg supersonic flight.

$20 \mathrm{~dB}$ from point-to-point) due to the increased number of possible ray paths. The spreading of the actual obser- vations (at the same range, but for different observed phases) is about one order of pressure magnitude, corre- 
sponding to $20 \mathrm{~dB}$ and thus favoring the elevated source as the most likely source.

The ray tracing amplitudes shown can fairly well describe the general attenuation of amplitudes with distance, however, their variance with respect to one particular geometric spreading loss is extremely low. While raytracing was very successful in the kinematic description of the observed arrivals, it seems inadequate for resolving their dynamic properties. The bounds given by the minimum and maximum spreading loss considered, however do to some extent capture the variability of the observed arrival amplitudes and may hint at wave theoretical effects being the reason for the amplitude variability. Overall, the accomplishments of this section outline a promising approach of using infrasound propagation modeling for the discrimination and identification of competing infrasound source hypotheses.

\section{Summary \& Conclusions}

Infrasound propagation modeling within this study was applied to a number of ground-truth field campaign measurements: a total of nine rocket engine test cases and two additional source scenarios. The field campaign consisted in the deployment of six microbarometers along a line profile between an infrasonic ground-truth source (Ariane 5 engine tests) and a CTBT-IMS infrasound array (IS26) covering the regional distance range up to 320 $\mathrm{km}$ and including the acoustic shadow zone [27]. The engine tests were proved to be an ideal infrasound ground-truth source with a continuous, stable and ergodic signal emission with a clearly defined duration and precise localization. The different tests during different months and seasons provided a valuable data basis for field campaign observations and corresponding model efforts focusing on dynamic effects in infrasound propagation. The additional source scenarios were based on the investigation of the signatures of a surface explosion or a supersonic flight both reported to have occurred at the same time and in the same general region.

Detailed propagation modeling from near source to regional distances was applied by using ray-tracing and parabolic equation methods. It was thereby possible to precisely estimate the infrasound ducting behavior through the troposphere and stratosphere and also to take into account small-scale atmospheric disturbances like gravity waves. Modeling results were found to be in good accordance with the observations.

The application of propagation modeling successfully verified the observation of tropospheric ducting in four different test cases. For two of these cases, a duct of a few hundred meters altitude entailed observation distances of 30 - $50 \mathrm{~km}$, for the other two cases, a duct of 3 $4 \mathrm{~km}$ altitude implicated unusually large distances of 120
- $180 \mathrm{~km}$. The observed celerities and amplitudes at these distances are too large to be of stratospheric origin and propagation modeling indeed confirms this. Propagation modeling was furthermore applied to estimate sound pressure amplitudes along the propagation path and also to compare modeling results with the observations quantitatively, i.e. explaining the observed amplitude characteristics.

The inclusion of fine-scale structures as an expression of atmospheric dynamics [19,22] in the modeling of infrasound propagation by considering effective sound speed variations due to gravity waves allowed a more realistic modeling of the atmospheric conditions and the resulting infrasound ducting behavior. The comparison of modeling and observed amplitudes in the different test cases as well as the size estimation and appearance of infrasonic ducting regions and shadow zones was improved by this approach. Root mean square deviations were calculated between observed and modeled amplitudes and showed improvements of $20 \%$ - 40\% when considering one-dimensional gravity wave disturbances of the effective sound speed background. Improvements of up to $90 \%$ were estimated when using multiple gravity wave profiles, one for each sensor, as a proxy for the effects of higher-dimensional variability of the atmospheric background that exceeded the capabilities of the propagation models used in this study. The good agreement of measurements and modeling was also underlined by a complete and correct explanation of all detections at the line profile stations and at IS26. In two cases after the end of the winter season, in April and in May 2012, stratospheric arrivals observed at IS26 could only be explained in modeling by including gravity wave perturbations in the atmospheric background model. Using an ensemble of gravity wave models to define the extent of ducting regions and shadow zones resulted in a higher confidence in our ability of explaining observations with propagation modeling, thus validating and verifying the infrasound measurements.

Infrasound source discrimination using propagation modeling was furthermore described in this study. By investigating the propagation behavior for two different source scenarios, a transient signal at the same day as one of the engine tests was successfully associated with a supersonic flight infrasound source in contrast to a competing ground-based explosion. The elevated infrasound source was identified by ducting behavior, amplitude and travel time estimations from the propagation models as preferential explanation for the observed signals.

Propagation modeling within this study was applied to the validation of infrasound measurements, examination of ducting behavior and discrimination of sources at local and regional distances and through the acoustic shadow zone. It demonstrated its benefit in these fields by achieving a good agreement with observations from well- 
constrained ground-truth sources. By describing atmospheric background conditions with high resolution, including fine-scale variations by an ensemble of gravity waves, even observations not expected from the standard model could be well explained and the realistic state of the atmosphere could be well represented by the approach followed within this study.

Further investigations combining propagation modeling with infrasound observations should include the representation of multi-dimensional background conditions in state of the art propagation models at high spatial and temporal resolution, consideration of small-scale influences due to e.g. orography and near surface irregularities as well as an increased representation and understanding of gravity waves and their influence on atmospheric dynamics. Results of such studies are invaluable for improving infrasound detection capabilities, atmospheric models and the understanding of infrasound processes on different scales.

\section{Acknowledgements}

We thank the counterpart from German Aerospace Center Lampoldshausen (DLR-RA), the colleagues from the State Seismological Survey of Baden-Württemberg (LEDBW), and the German Airforce (Bundeswehr, Luftwaffenamt, Flugbetriebs-und Informationszentrale, FLIZ) for providing information, data and support to this study.

We are grateful to Edgar Wetzig and Uwe Stelling for their support in installing and maintaining the mobile infrasound stations during the field campaign.

This work was partly performed in the course of the ARISE collaborative project within the Seventh Framework Programme funded by the European Union (http://arise-project.eu/).

\section{REFERENCES}

[1] R. Matoza, J. Vergoz, A. Le Pichon, L. Ceranna, D. N. Green, L. G. Evers, M. Ripepe, P. Campus, L. Liszka, T. Kvaerna, E. Kjartansson and A. Höskuldsson, "LongRange Acoustic Observations of the Eyjafjallajökull Eruption, Iceland, April-May 2010," Geophysical Research Letters, Vol. 38, No. 6, 2011, Article ID: L06308. http://dx.doi.org/10.1029/2011GL047019

[2] D. Tailpied, A. Le Pichon, E. Marchetti, M. Ripepe, M. Kallel and L. Ceranna, "Remote Infrasound Monitoring of Mount Etna: Observed and Predicted Network Detection Capability," InfraMatics, Vol. 2, No. 1, 2013, pp. 111. http://dx.doi.org/10.4236/inframatics.2013.21001

[3] A. Le Pichon, L. Ceranna, C. Pilger, P. Mialle, D. Brown, P. Herry and N. Brachet, "The 2013 Russian Fireball Largest Ever Detected by CTBTO Infrasound Sensors," Geophysical Research Letters, Vol. 40, No. 14, 2013, pp. 3732-3736. http://dx.doi.org/10.1002/grl.50619

[4] C. D. de Groot-Hedlin, M. A. H. Hedlin, K. T. Walker, D.
P. Drob and M. A. Zumberge, "Evaluation of Infrasound Signals from the Shuttle Atlantis Using a Large Seismic Network," Journal of the Acoustical Society of America, Vol. 124, No. 3, 2008, pp. 1442-1451.

http://dx.doi.org/10.1121/1.2956475

[5] L. Ottemöller and L. G. Evers, "Seismo-Acoustic Analysis of the Buncefield Oil Depot Explosion in the UK, 2005 December 11," Geophysical Journal International, Vol. 172, No. 3, 2008, pp. 1123-1134.

http://dx.doi.org/10.1111/j.1365-246X.2007.03701.x

[6] L. Ceranna, A. Le Pichon, D. N. Green and P. Mialle, "The Buncefield Explosion: A Benchmark for Infrasound Analysis across Central Europe," Geophysical Journal International, Vol. 177, No. 2, 2009, pp. 491-508. http://dx.doi.org/10.1111/j.1365-246X.2008.03998.x

[7] P. Campus, "The IMS Infrasound Network and Its Potential for Detection of Events: Examples of a Variety of Signals Recorded around the World," InfraMatics, Vol. 6, No. 1, 2004, pp. 13-22.

[8] A. Le Pichon, E. Blanc and A. Hauchecorne, "Infrasound Monitoring for Atmospheric Studies," Springer, Berlin, 2010.

[9] M. A. H. Hedlin, K. T. Walker, D. P. Drob and C. D. de Groot-Hedlin, "Infrasound: Connecting the Solid Earth, Oceans, and Atmosphere," Annual Review of Earth and Planetary Sciences, Vol. 40, 2012, pp. 327-254.

http://dx.doi.org/10.1146/annurev-earth-042711-105508

[10] M. A. Garces, "On Infrasound Standards, Part 1: Time, Frequency, and Energy Scaling," InfraMatics, Vol. 2, No. 2, 2013, pp. 13-35.

http://dx.doi.org/10.4236/inframatics.2013.22002

[11] A. Le Pichon, E. Blanc and D. P. Drob, "Probing HighAltitude Winds Using Infrasound," Journal of Geophysical Research, Vol. 110, No. D20, 2005, Article ID: D20104.

[12] D. P. Drob, R. R. Meier, J. M. Picone and M. A. Garces, "Inversion of Infrasound Signals for Passive Atmospheric Remote Sensing," In: A. Le Pichon, E. Blanc, and A. Hauchecorne, Eds., Infrasound Monitoring for Atmospheric Studies, Springer, Berlin, 2010. http://dx.doi.org/10.1007/978-1-4020-9508-5_24

[13] J.-M. Lalande, O. Sèbe, M. Landès, P. Blanc-Benon, R. S. Matoza, A. Le Pichon and E. Blanc, "Infrasound Data Inversion for Atmospheric Sounding," Geophysical Journal Internationa, Vol. 190, No. 1, 2012, pp. 687-701. http://dx.doi.org/10.1111/j.1365-246X.2012.05518.x

[14] D. P. Drob, J. M. Picone and M. A. Garces, "Global Morphology of Infrasound Propagation," Journal of Geophysical Research, Vol. 108, No. D21, 2003, p. 4680.

[15] D. Norris and R. Gibson, "Numerical Methods to Model Infrasound Propagation through Realistic Specifications of the Atmosphere," In: A. Le Pichon, E. Blanc and A. Hauchecorne, Eds., Infrasound Monitoring for Atmospheric Studies, Springer, Berlin, 2010.

http://dx.doi.org/10.1007/978-1-4020-9508-5 17

[16] H. E. Bass, C. H. Hetzer and R. Raspet, "On the Speed of Sound in the Atmosphere as a Function of Altitude and Frequency," Journal of Geophysical Research, Vol. 112, No. D15, 2007, Article ID: D15110. 
http://dx.doi.org/10.1029/2006JD007806

[17] P. T. Negraru, P. Golden and E. T. Herrin, "Infrasound Propagation in the 'Zone of Silence'," Seismological Research Letters, Vol. 81, No. 4, 2010, pp. 614-624.

http://dx.doi.org/10.1785/gssrl.81.4.614

[18] L. G. Evers, A. R. J. van Geyt, P. Smets and J. T. Fricke, "Anomalous Infrasound Propagation in a Hot Stratosphere and the Existence of Extremely Small Shadow Zones," Journal of Geophysical Research, Vol. 117, No. D06, 2012, Article ID: D06120. http://dx.doi.org/10.1029/2011JD017014

[19] S. N. Kulichkov, I. P. Chunchuzov and O. I. Popov, "Simulating the Influence of an Atmospheric Fine Inhomogeneous Structure on Long-Range Propagation of Pulsed Acoustic Signals," Izvestiya Atmospheric and Oceanic Physics, Vol. 46, No. 1, 2010, pp. 60-68.

[20] D. N. Green, J. Vergoz, R. Gibson, A. Le Pichon and L. Ceranna, "Infrasound Radiated by the Gerdec and Chelopechene Explosions: Propagation along Unexpected Paths," Geophysical Journal International, Vol. 185, No. 2, 2011, pp. 890-910. http://dx.doi.org/10.1111/j.1365-246X.2011.04975.x

[21] I. P. Chunchuzov, S. N. Kulichkov, O. Popov, R. Waxler and J. Assink, "Scattering of Infrasound by Anisotropic Inhomogenities of the Atmosphere," Izvestiya Atmospheric and Oceanic Physics, Vol. 47, No. 5, 2011, pp. 540547.

[22] D. P. Drob, D. Broutman, M. A. H. Hedlin, N. W. Winslow and R. G. Gibson, "A Method for Specifying Atmospheric Gravity Wavefields for Long-Range Infrasound Propagation Calculations," Journal of Geophysical Research, Vol. 118, No. 10, 2013, pp. 3933-3943.

[23] K. Koch, "Analysis of Signals from an Unique GroundTruth Infrasound Source Observed at IMS Station IS26 in Southern Germany," Pure and Applied Geophysics, Vol. 167, No. 4-5, 2010, pp. 401-412. http://dx.doi.org/10.1007/s00024-009-0031-2

[24] C. Pilger and M. Bittner, "Infrasound from Tropospheric Sources: Impact on Mesopause Temperature?" Journal of Atmospheric and Solar-Terrestrial Physics, Vol. 71, No. 8-9, 2009, pp. 816-822. http://dx.doi.org/10.1016/j.jastp.2009.03.008

[25] R. Gibson and D. Norris, "InfraMAP: Development of an Infrasound Propagation Modeling Toolkit," Technical Report, DTRA, 2002.

[26] A. Le Pichon, J. Vergoz, P. Herry and L. Ceranna, "Analyzing the Detection Capability of Infrasound Arrays in Central Europe," Journal of Geophysical Research, Vol. 113, No. D12, 2008, Article ID: D12115. http://dx.doi.org/10.1029/2007JD009509

[27] K. Koch, "Regional Infrasound Observations from Recent
Rocket Engine Tests in Southern Germany," 2012 Monitoring Research Review: Ground-Based Nuclear Explosion Monitoring Technologies, 2012, pp. 710-720.

[28] R. M. Jones, J. P. Riley and T. M. Georges, "HARPA: A Versatile Three-Dimensional Hamiltonian Ray-Tracing Program for Acoustic Waves in the Atmosphere above Irregular Terrain,” Technical Report, NOAA, 1986.

[29] D. P. Drob and 21 Co-Authors, "An Empirical Model of the Earth's Horizontal Wind Fields: HWM07," Journal of Geophysical Research, Vol. 113, No. A12, 2008, Article ID: A12304. http://dx.doi.org/10.1029/2008JA013668

[30] J. M. Picone, A. E. Hedin, D. P. Drob and A. C. Aikin, "NRLMSISE-00 Empirical Model of the Atmosphere: Statistical Comparisons and Scientific Issues," Journal of Geophysical Research, Vol. 107, No. , 2002, pp. 14681483. http://dx.doi.org/10.1029/2002JA009430

[31] C. S. Gardner, C. A. Hostetler and S. J. Franke, "Gravity Wave Models for the Horizontal Wave Number Spectra of Atmospheric Velocity and density Fluctuations," Journal of Geophysical Research, Vol. 98, No. D1, 1993, pp. 1035-1049. http://dx.doi.org/10.1029/92JD02051

[32] D. C. Fritts and M. J. Alexander, "Gravity Wave Dynamics and Effects in the Middle Atmosphere," Reviews of Geophysics, Vol. 41, No. 3, 2003, pp. 1-64.

[33] M. H. McKenna, R. G. Gibson, B. E. Walker, J. McKenna, N. W. Winslow and A. S. Kofford, "Topographic Effects on Infrasound Propagation," Journal of the Acoustical Society of America, Vol. 131, No. 1, 2012, pp. 35-46. http://dx.doi.org/10.1121/1.3664099

[34] N. Brachet, D. Brown, R. Le Bras, Y. Cansi, P. Mialle and J. Coyne, "Monitoring the Earth's Atmosphere with the Global IMS Infrasound Network," In: A. Le Pichon, E. Blanc and A. Hauchecorne, Eds., Infrasound Monitoring for Atmospheric Studies, Springer, Berlin, 2010. http://dx.doi.org/10.1007/978-1-4020-9508-5_3

[35] A. Le Pichon, L. Ceranna and J. Vergoz, "Incorporating Numerical Modeling into Estimates of the Detection Capability of the IMS Infrasound Network," Journal of Geophysical Research, Vol. 117, No. D5, 2012, Article ID: D05121. http://dx.doi.org/10.1029/2011JD016670

[36] I. P. Chunchuzov, S. N. Kulichkov, V. Perepelkin, A. Ziemann, K. Arnold and A. Kniffka, "Mesoscale Variations in Acoustic Signals Induced by Atmospheric Gravity Waves," Journal of the Acoustical Society of America, Vol. 125, No. 2, 2009, pp. 651-664. http://dx.doi.org/10.1121/1.3056477

[37] M. A. H. Hedlin and K. T. Walker, "A Study of Infrasonic Anisotropy and Multipathing in the Atmosphere Using Seismic Networks," Philosophical Transactions of the Royal Society A, Vol. 371, No. 1984, 2013, Article ID: 20110542. http://dx.doi.org/10.1098/rsta.2011.0542 